\title{
Wave Energy Converters
}

\author{
Judicaël Aubry, Hamid Ben Ahmed, Bernard Multon, \\ Aurélien BABARIT and Alain CLÉMENT.
}

Long before scientists ever put forward a reasoned description of the phenomenon based on fluid mechanics equations, men were aware of the power of ocean waves through observing natural phenomena. This awareness came from navigating at sea and coming into contact with the infamous "freak waves", or from experiencing the damage caused onshore by storm breakers and tsunamis. The first written record of the desire to exploit this energy, that we have been able to find, is in a French patent dated 1799, entitled: "Pour divers moyen d'employer les vagues de la mer comme moteurs" (Various means of using ocean waves as driving forces) by Messrs. Girard, father and son. We can find traces of other attempts to exploit wave energy in California in the $19^{\text {th }}$ Century, where the Wave-Power AirCompressing Company in San Francisco built a "wave motor" designed by the American inventor Terence Duffy under a pontoon. At the beginning of the $20^{\text {th }}$ Century, a French engineer, Paul Grasset, conceived of a wave energy conversion process he called the bélier-siphon barométrique (barometric ram-siphon) and commissioned the building of a test station on the coast, to harness what he termed the "impulsions produced by the sea". Unfortunately, the economic crisis of 1929, followed by the Second World War, would prevent him from finishing his "marine hydrodynamic laboratory", the ruins of which can still be seen on Cape Saint Martin, at the foot of the Biarritz lighthouse.

The world waited until the first oil crisis of 1973 for academics to begin to reexamine the question of harnessing wave energy. It was an article by Professor S. Salter [SAL 74] of the University of Edinburgh, published in the journal Nature in 
1974, and simply entitled "Wave Power", that marked a turning point and reawakened scientific interest. This resurgence of research into wave energy conversion machines, at the time, was concentrated mainly in European countries and Japan. [CLE 02] contains an overview of the development of such technology in Europe in the late $20^{\text {th }}$ Century. Since then, the number of projects has increased considerably, and the research effort has spread to other continents. An up-to-date summary of the main technologies used can be found in [FAL 10].

\subsection{Presentation of the wave energy resource}



Figure 11.1. Mechanism of the creation of waves

The waves are a by-product of the wind, which in itself is a by-product of solar energy. The wind creates movement in the upper layer of the water in open sea, giving an undulating form to the surface. These undulations are very small at first, then increase in size as the wind continues to blow and separate waves merge to form larger ones; there is an exchange of energy associated with this. They propagate in the form of gravity waves, with very little loss of energy, as long as the depth of the water is greater than the wavelength. Thus, waves are created in the open ocean, and the energy they contain is dissipated when they approach the coast, in shallower waters. Note that here, we speak of swell and waves synonymously; the difference between these two terms lies in the spectral typology relating to sea states (their distribution in terms of frequency and direction), but has no bearing on our argument.

The energy transported by waves is the sum, in equal parts, of kinetic energy linked to the velocity field of water particles, and potential energy linked to the deformation of the fluid environment around its position on the surface plane. Thus, it is mechanical energy. 
Wave power is defined by the flow of energy through a vertical surface perpendicular to the direction of its propagation. It could therefore be expressed in $W \cdot m^{-2}$. However, this is not the usual usage, and it is preferable to quantify wave power in $W . m^{-1}$ (watts per meter of wave front), vertically integrating the power per surface from the bottom of the ocean to the surface, thanks to the fact that the kinematic of flow at depth is known if its value at the surface is known. For infinite depth, $95 \%$ of the energy of the wave is contained in a depth equal to half its wavelength. The wavelength is typically between 60 and $160 \mathrm{~m}$.

Wave power, expressed in watts per meter of wave front, is the flow of energy passing through a surface perpendicular to the direction of propagation of the waves per unit time. In order to determine this flow of energy, it is useful to calculate the mechanical energy of a vertical column of water which has a base of unitary surface area, and then to multiply it by the group speed of the wave. The mechanical energy of a column of water is the sum of its potential and kinetic energy. For the loss-free propagation of such a wave, it has been shown that the average value of these two types of energy are equal, and are written as follows in the case of a wave with sinusoidal deformation [GUY 01]:

$$
\left\langle E_{k}(t)\right\rangle=\left\langle E_{p}(t)\right\rangle=\frac{E_{m}}{2}=\frac{\rho_{w} g H^{2}}{16}
$$

where $\rho_{w}$ is the density of seawater (which depends on the salinity, $\left.\approx 1,025 \mathrm{~kg} \cdot \mathrm{m}^{-3}\right), \mathrm{g}$ is gravity and $H$ is the height from crest to trough of the deformation. When the depth of the water is infinite, the group speed (i.e. speed of energy propagation) is written:

$$
v_{g}(T)=\frac{g T}{4 \pi}
$$

where $T$ is the period of the sinusoidal wave.

The power per meter of wave front of a sinusoidal wave is therefore equal to:

$$
P_{w}=E_{m} v_{g}=\frac{\rho_{w} g^{2}}{32 \pi} H^{2} T \approx 980 H^{2} T\left(W \cdot m^{-1}\right)
$$

Equation [11.3] is valid for a unidirectional and sinusoidal wave. 


\subsubsection{Taking the spectral nature of the swell into account}

Swell at sea is more complex than a unidirectional and monochromatic wave (containing only one frequency). It is helpful to consider that it may be represented by superimposing its component waves on one another, and therefore the study of swell at sea involves studying its spectrum.

Spectral characterization of swell is an important field of scientific study. It is not our intention to give a detailed overview of this area here, merely to provide some information on the subject.

The characterization of real swell is based on the spectral study of the signal $\eta(t)$ of elevation of the level of free surface at a fixed point. Its power spectral density is denoted $S_{\eta}(f)$. The power per meter of wave front of the swell is expressed as in [SAU 09]:

$$
P_{w}=\rho g \int_{0}^{\infty} S_{\eta}(f) v_{g}(f) d f
$$

We define $m_{n}$, the spectral moment of the order $n$ of $S_{\eta}(f)$ :

$$
m_{n}=\int_{0}^{\infty} f^{n} S_{\eta}(f) d f
$$

For an infinite depth of water, equation [11.4] can be simplified using formula [11.2] and can be written in the following manner:

$$
P_{w}=\frac{\rho_{w} g^{2}}{4 \pi} m_{-1}
$$

The energy period $T_{e}$ is then defined by:

$$
T_{e}=\frac{m_{-1}}{m_{0}}
$$

The significant wave height $H_{s}$ is related to the variance $m_{0}$ by:

$$
H_{s}=4 \sqrt{m_{0}}
$$


Formula [11.6] then becomes:

$$
P_{w}=\frac{\rho_{w} g^{2}}{64 \pi} H_{s}^{2} T_{e} \approx 490 H_{s}^{2} T_{e}\left(W \cdot m^{-1}\right)
$$

Standardized spectra were defined, enabling us to come close to the spectrum measured in situ and thus obtain a simple spectral model which can be used to generate a numerical reconstruction of the signal. Thus, the ISSC (International Ship Structure Committee [MIC 99]) spectrum is written as follows:

$$
S_{I S S C}(f)=\frac{5}{16} H_{s}^{2} \frac{f_{p}^{4}}{f^{5}} e^{-\frac{5}{4} \frac{f_{p}^{4}}{f^{4}}}
$$

The peak frequency $f_{p}$ corresponds to the frequency for which $S_{I S S C}(f)$ is maximum. It may be linked to the energy period by the relation:

$$
f_{p}=\left(\frac{3}{5}\right)^{1 / 4} \frac{1}{T_{e}}
$$

The pair of parameters $\left(H_{s}, f_{p}\right)$ (or $\left(H_{s}, T_{p}\right)$ with $T_{p}=1 / f_{p}$ called peak period) defines what is known as a sea state. In practice, the spectrum of the swell is taken to be stationary over a duration of about an hour. The sea state is therefore a characterization of the swell over this period of time, considering its energetic characteristics as statistically stable over that time.

Note that, at this simplified level of representation, the level of energetic resource of a sea state must be defined according to two statistical parameters: the height and the period of the waves, while for other forms of renewable mechanical energy, e.g. wind power, one is enough (for instance, the wind speed).

\subsubsection{Chart of the occurrence of sea states}

Wave measurement buoys installed out at sea allow us to generate diagrams of the probability of occurrence of sea states for different points of the French coast. Figure 11.2 shows an example of data collected near to the isle of Yeu in the Bay of Biscay, and Figure 11.3, the average annual wave power of each sea state found by weighting the power per meter of wave front (equation [11.9]) by the probability of the occurrence of each sea state (Figure 11.2). In the case of the site at the isle of Yeu, although there are two peaks of probability of sea states $\left(\left(H_{s}=1 \mathrm{~m}, T_{p}=8 \mathrm{~s}\right)\right.$ and $\left.\left(H_{s}=3 \mathrm{~m}, T_{p}=9.5 \mathrm{~s}\right)\right)$, which presents the greatest energetic potential is around $\left(H_{s}=3.5 \mathrm{~m}, T_{p}=9 \mathrm{~s}\right)$. 
In France, the Centre d'Archivage National de Données de Houle In-Situ (CANDHIS - National Archive of In-Situ Wave Data) has a network of wave measurement buoys and creates archives of measurements of sea states.

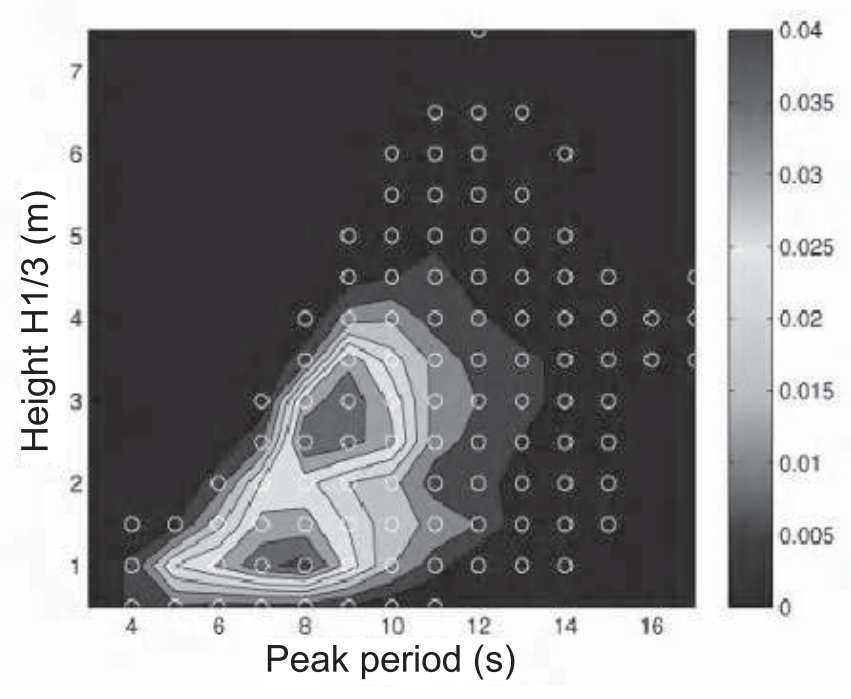

Figure 11.2. Probability of occurrence of different sea states (site at the isle of Yeu) (for a color version of this figure please see www.iste.co.uk/multon/marine.zip/)

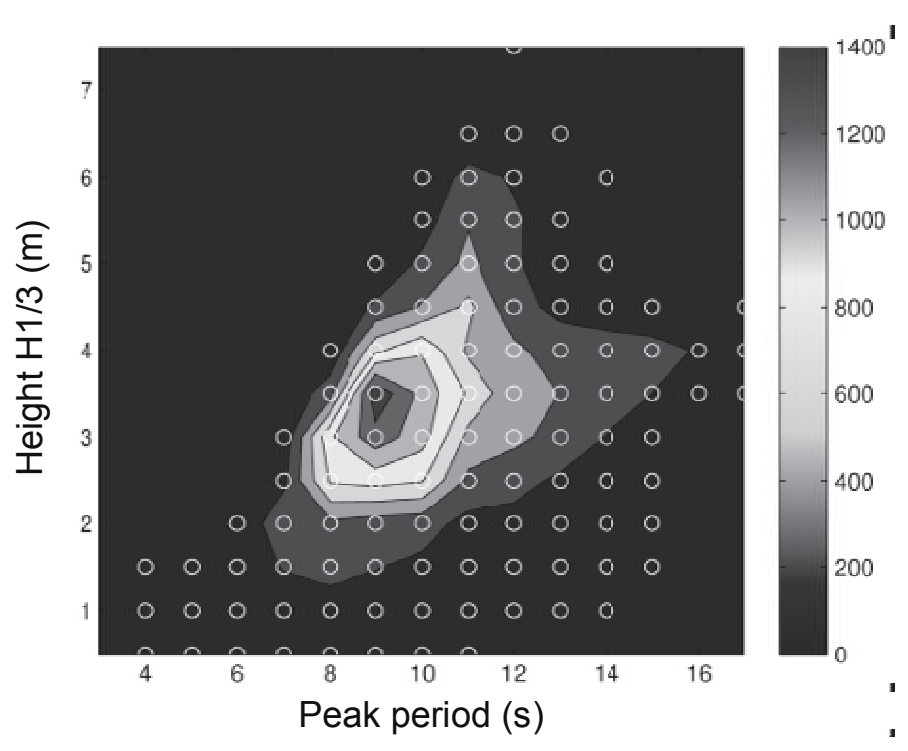

Figure 11.3. Average annual wave power $(\mathrm{W} / \mathrm{m})$ depending on the sea state $\left(H_{s}, T_{p}\right)$ at the isle of Yeu site. The power of waves weighted by the probability of occurrence (for a color version of this figure please see www.iste.co.uk/multon/marine.zip/)

\subsubsection{Geographic distribution}

Figure 11.4 presents the worldwide distribution of average annual wave power in $\mathrm{kW} / \mathrm{m}$. The maximum, around $100 \mathrm{~kW} / \mathrm{m}$, is found around Cape Horn. Note that 
huge areas of the globe have densities of wave power greater than $20 \mathrm{~kW} / \mathrm{m}$, which is generally accepted as the profitability threshold for wave energy converters. Some of the most exposed areas are found in the North Atlantic, southern Australia and on the Pacific coast of South America. The seasonal variance of the wave energy resource is, however, far more marked in the northern hemisphere.

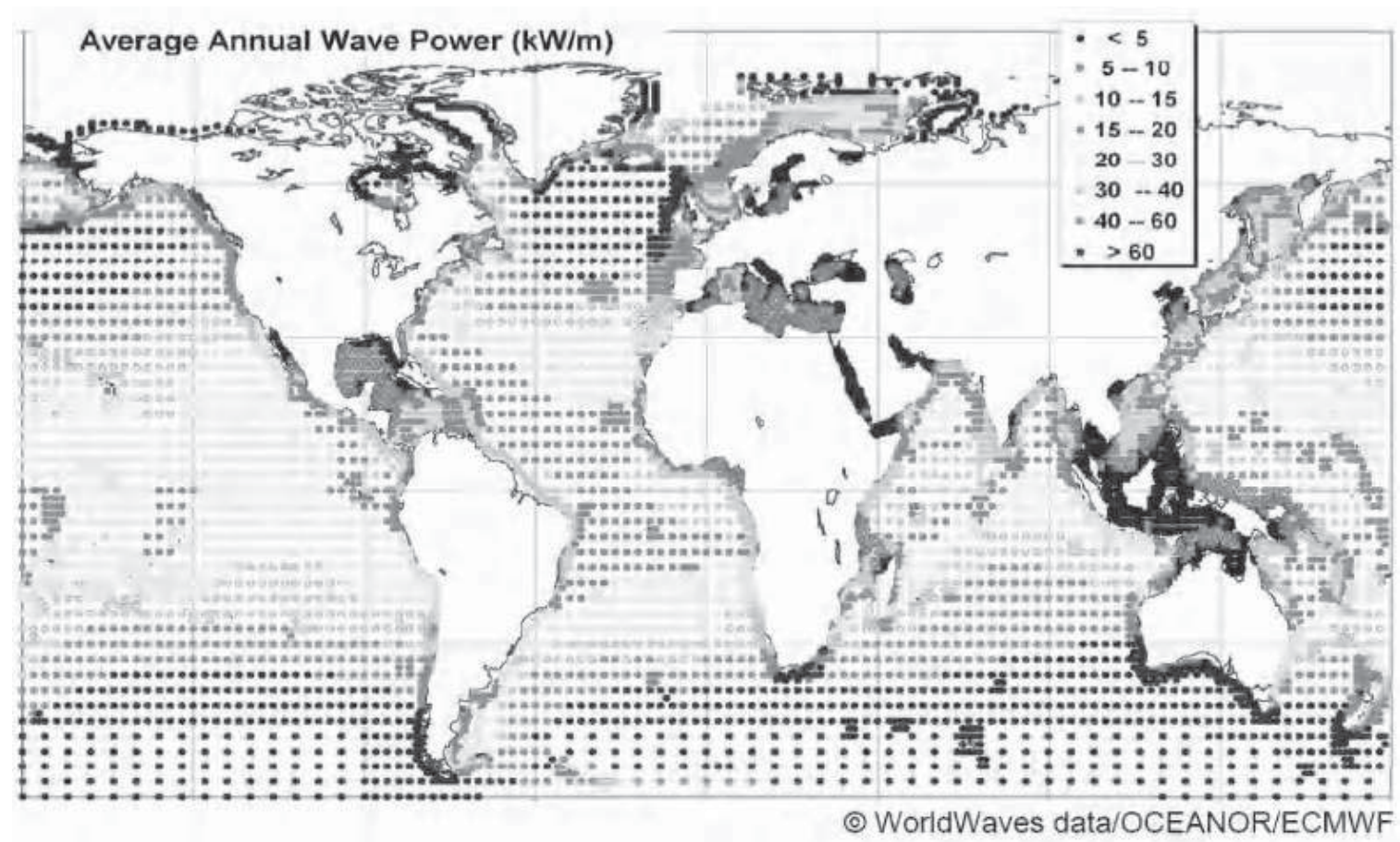

Figure 11.4. Worldwide distribution of the wave energy resource [CRU 08](for a color version of this figure please see www.iste.co.uk/multon/marine.zip/)

It is in Europe that the first wave energy converters were developed, with the main drive coming from the British. Britain, along with Ireland, has the greatest exposure to the wave energy resource in that area of the globe. The average annual wave power on the Atlantic coast of Europe varies between 15 and $80 \mathrm{~kW} . \mathrm{m}^{-1}$. In France, it is around $40 \mathrm{~kW} \cdot \mathrm{m}^{-1}$ in the Bay of Biscay. According to the World Energy Council [THO 04], the economically accessible global potential is between 140 and $750 \mathrm{TWh}$.

\subsection{Classification of wave energy converters}

There are numerous criteria which can be used to draw up classifications. The first relates to the shape of the device [DRE 09]. Thus, we can distinguish three types of geometry:

- "Point absorbers" are axisymmetrical devices which are small in relation to the wavelength. 
- "Terminators" are very large horizontally. Their main axis is perpendicular to the propagation direction of the waves.

- "Attenuators" are also horizontally large. They function in line with the direction of propagation of the waves. The Pelamis system is an example of an attenuator.

A second possible means of classification relates to the location of the machines, which may be:

- "Onshore" systems are generally connected to the shore or to a manmade construction (e.g. a breakwater). They are relatively easy to maintain and to link into the electrical grid, which does not require submarine power cables to be laid. However, the available wave energy resource decreases as the depth of the water becomes less.

- "Nearshore" (between approximately 0.5 and $2 \mathrm{~km}$ out to sea) areas may offer the advantage of a fairly small bathymetric depth (around $1 / 4$ of the wavelength) which enables submerged wave energy converters to be bottom-mounted, but relatively near to the shore. This characteristic enables the energy to be transported to the coast via pressurized fluid. The wave energy resource is greater than onshore, but less than in the open ocean. However, studies have shown that the decrease in energetic potential is relatively small (around $10 \%$ of the resource off the coast) but that the probability of extreme sea states is also reduced, which relieves the constraints at the design stage in terms of the durability of the installation [FOL 09].

- "Offshore" is, several kilometers from shore. The bathymetry at this distance is generally greater than $1 / 3$ of the wavelength and the wave energy resource is not reduced. Transmission of the energy to shore can only be done in the form of electricity, at a voltage of around $10 \mathrm{kV}$ so as to reduce line losses. It becomes essential to link the wave energy converters to one another in order to have just one submarine power cable running from the farm to the coast.

One final classification, which we shall use for the remainder of this section, is based on the principles of hydro-mechanical conversion used by the machines. Beyond a small number of unclassifiable processes, we can thus distinguish three main types of conversion principles:

- overtopping devices: type A;

- oscillating water column (OWC): type B;

- oscillating bodies on or under the surface: type $C$.

This latter classification, which currently appears to be the most pertinent, was adopted by Falcão in a recent study, from which the diagrammatic overview is shown in Figure 11.5. 


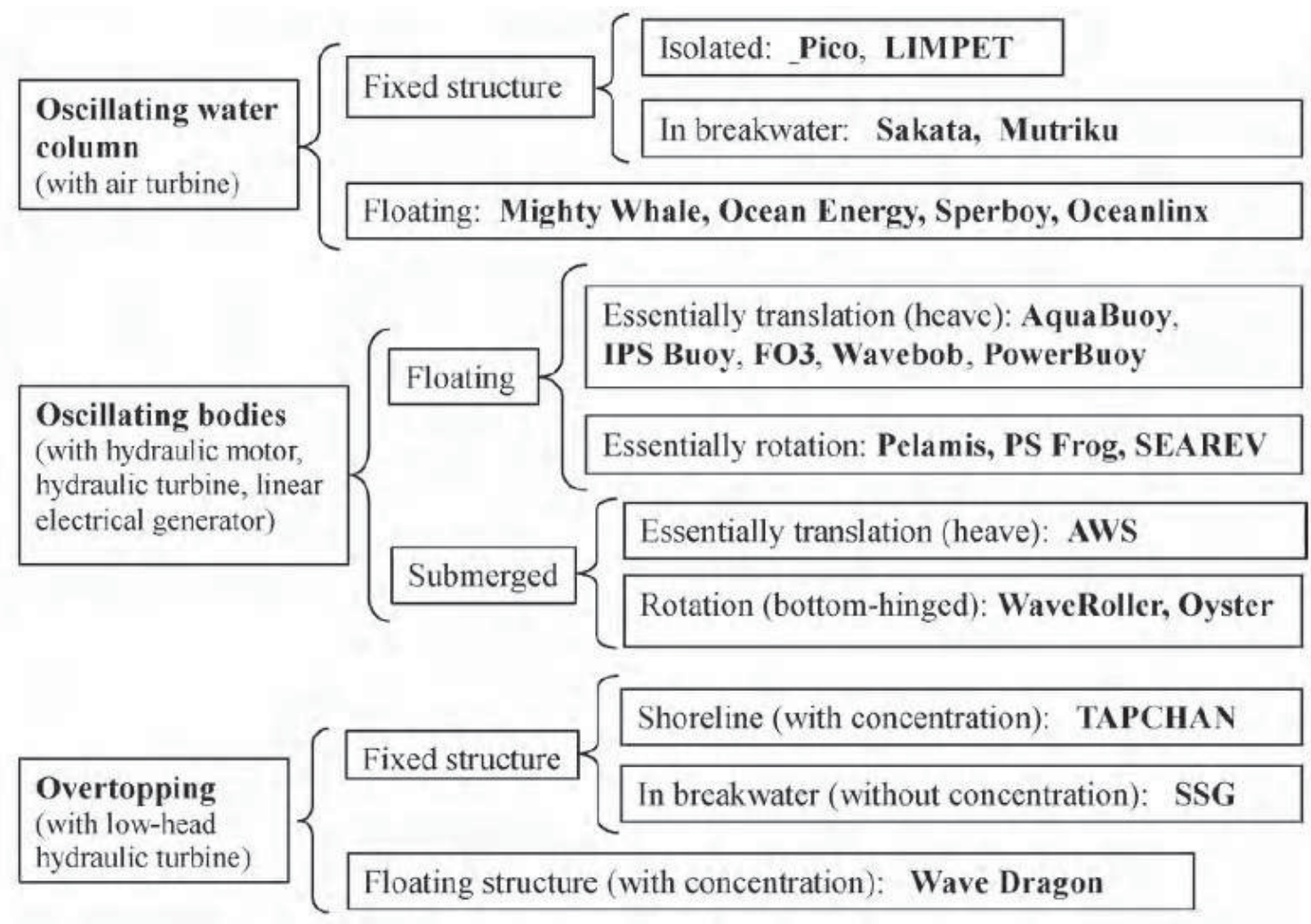

Figure 11.5. Classification put forward by Falcão [FAL 10]

Each of these principles of hydro-mechanical conversion transforms the incident wave energy into mechanical energy. This mechanical energy is null unless the mechanical movement is damped by an energy conversion system ${ }^{1}$. In order to carry out this recuperative damping or braking, these principles of hydro-mechanical conversion, which are discussed in the following section, must be associated with a mechanical-electric conversion chain. We can class the principles of mechanicalelectrical conversion into five categories:

- Continuous rotation, the conversion can be carried out by a rotating generator with energy smoothing built into the rotating parts (type 1) or with no smoothing if the moment of inertia and speed of rotation are not great enough to store sufficient rotational kinetic energy (type 2).

- Rotation or oscillatory shifting around a neutral position. The conversion can be achieved via a hydro-pneumatic or oleo-pneumatic conversion system (type 3). This means that pneumatic storage can be employed. The conversion can also be carried out directly by an electrical generator preceded by mechanical adaptation of the movement (rack and pinion transmission, gearbox, ball screw, etc.) (type 4), or simply in direct drive (type 5).

1 This is generally denoted by the letters PTO, for "power take off". 


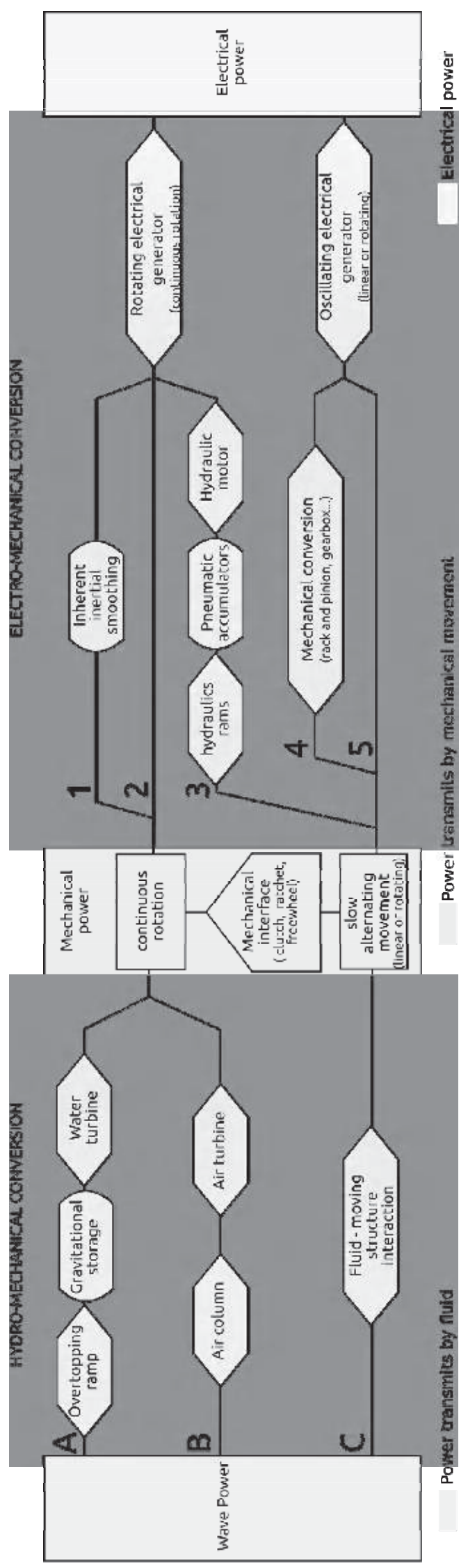

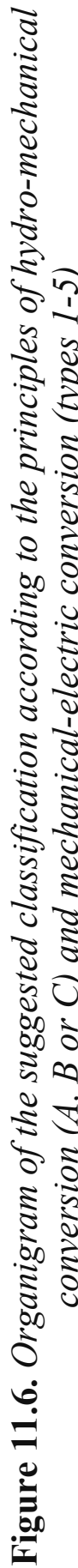


Thus, we suggest a two-entry classification system, on the one hand based on the principles of hydromechanical conversion (A, B and C) and on the other hand based on the principles of mechanical-electrical conversion (types 1 to 5). Figure 11.6 is a graphic representation of the 15 possibilities thus obtained. We shall use the following terminology:

- indirect wave energy converters, for systems with a type $A$ or $B$ indirect hydro-mechanical conversion system;

- direct wave energy converters, for systems with a type $C$ direct hydromechanical conversion system;

- wave energy converters with indirect mechanical-electric conversion, for systems with type 1-4 mechanical-electric conversion.

- wave energy converters with direct mechanical-electric conversion, for systems with type 5 mechanical-electric conversion.

\subsubsection{Overtopping systems: type A}

\subsubsection{Basic principles}

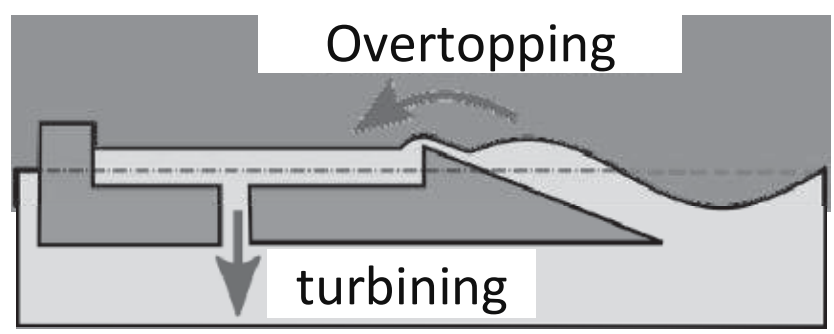

Figure 11.7. Principle of overtopping systems

These devices are designed to channel and concentrate waves in order to increase their height, and then let them break on a slope to fill a basin whose average level is above that of the sea (Figure 11.7). The water in the basin is then run back into the sea, driving low-head turbines connected to electrical generators. Similarly to the air turbines in oscillating water column systems (Figure 11.11), the use of variable speed technology means the yield energy remains high over a wide range of flowrates and head heights [KNA 00]. One of the advantages of this type of wave energy converter is that, by virtue of the principle upon which they operate, they have a reservoir of energy (gravitational potential energy storage), which can be used to ensure smoothing of the power produced. These systems do, however, have the disadvantage of having a startup threshold, because when the incident waves do not have enough energy to break over the top of the ramp, they produce 
no energy. In addition, when these installations are onshore, their effectiveness depends greatly on the tide level.

The mechanical-electrical energy conversion system (see Figure 11.6) usually found in these types of systems is type 2 .

\subsubsection{Examples}

The Tapchan (abbreviation for Tapered Channel, Figure 11.8), built in 1985 in Toftestallen (Norway), functioned for 6 years before being decommissioned following a storm in 1991. The quality of filling of the basin depends on the means height of the sea in relation to that of the basin. The narrowing of the channel in the Tapchan increases the height of the waves and fills a basin located several meters above sea level.

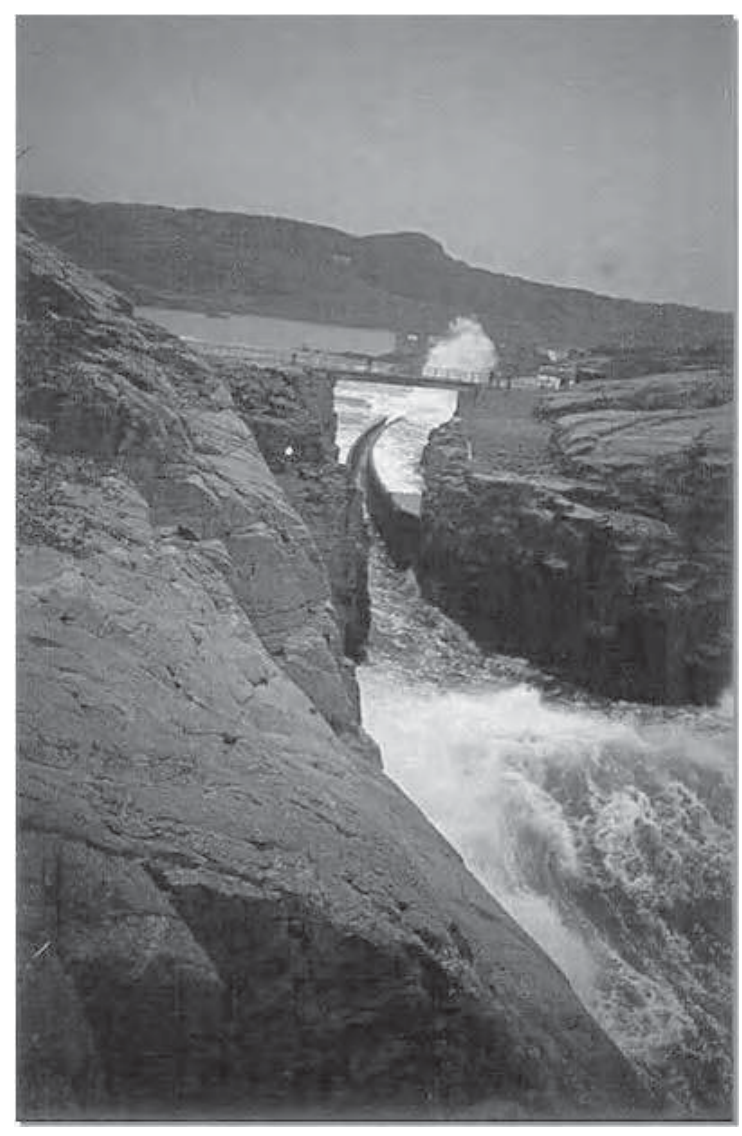

Figure 11.8. The Tapchan [FAL 93]

The Sea-wave Slot-cone Generator (SSG, Figure 11.9) design, from the Norwegian company Wave Energy, consists of using a number of ramps and basins located at different heights. This facilitates the exploitation of different wave heights for different water levels (tidal effect). The MST (multi-stage turbine) drives a single electrical generator. 


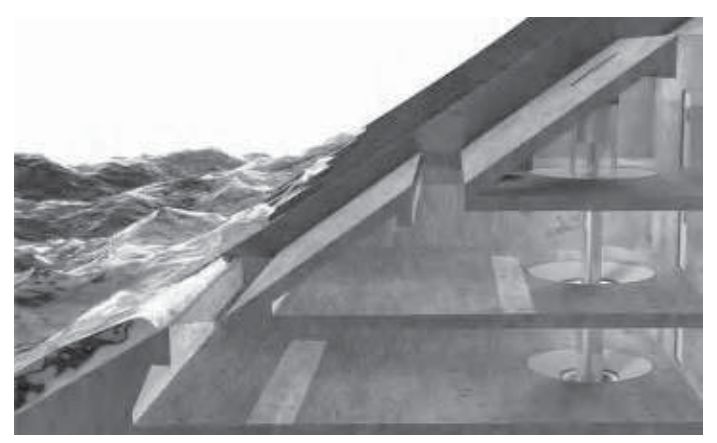

Figure 11.9. Sea-wave Slot-cone Generator [MAR 09]

The Wave Dragon wave energy converter (Figure 11.10) is a floating and moored device. Its floating height can be adjusted using ballast depending on the sea state. Two reflecting arms focus the swell and increase the crest height of the waves, which then break in a basin. The water in the basin drives low-head (Kaplan) turbines. It is interesting to run several low-powered turbines (in this case, 16 to 24), rather than one, which increases the yield energy depending on the available flowrate. Variable-speed electrical generators further increase the overall yield energy.

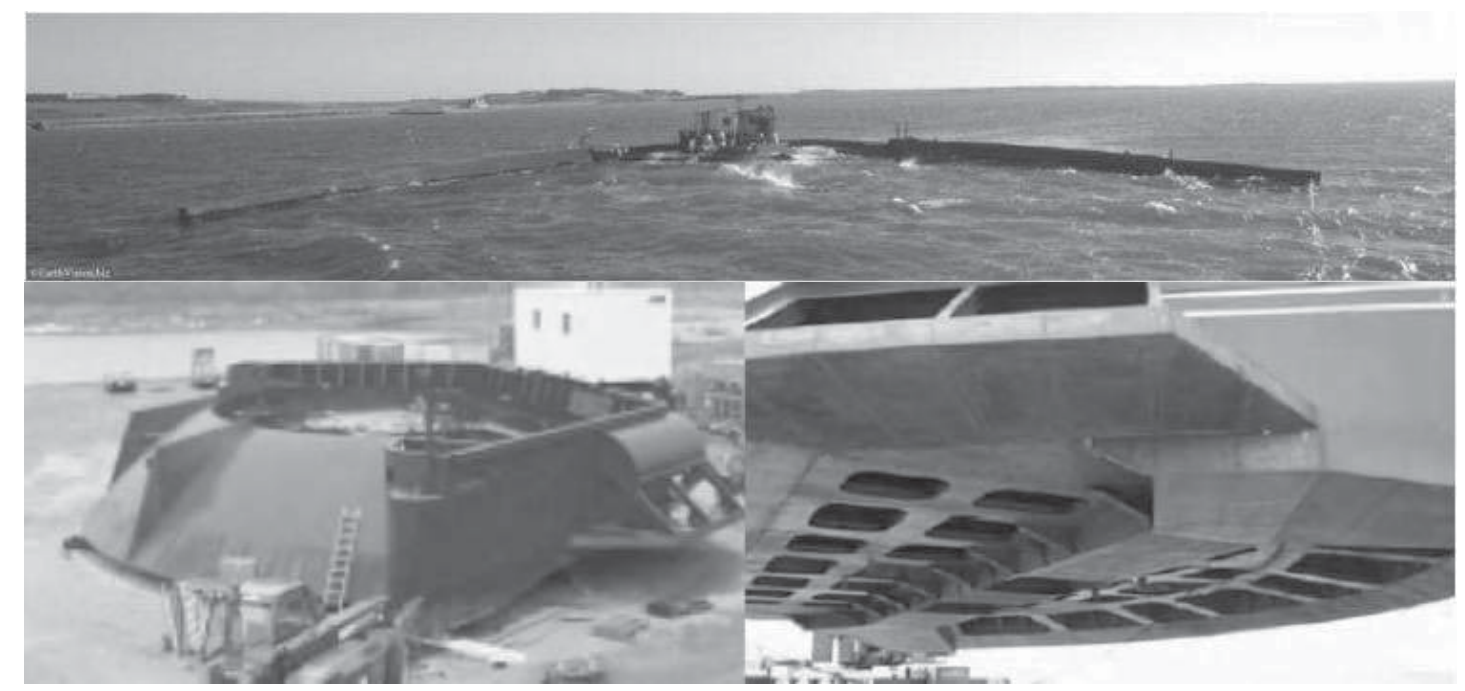

Figure 11.10. Wave Dragon, a floating offshore system. Above: the ensemble with the reflecting arms. Bottom left: the wave-breaking ramp and the filling basin. Bottom right: the compartments which allow the flotation height to be adjusted [KOF 06, CRU 08]

The full-scale version (1:1, still in the development phase in 2011) would have a $300 \mathrm{~m}$ wingspan (distance between the tips of the arms), be $170 \mathrm{~m}$ in length and $17 \mathrm{~m}$ in height, of which 3-6 m are above sea level. The total weight would be 33,000 tons, with an $8,000 \mathrm{~m}^{3}$ basin capacity. Its maximum power would be $7 \mathrm{MW}$, with annual productivity of $20 \mathrm{GWh}$ based on an average resource of $36 \mathrm{~kW} / \mathrm{m}$. 
Thus, the equivalent number of hours produced at full power would be around $2,800$. A reduced-scale prototype (1:4.5, or $57 \times 27 \mathrm{~m}$ and $237 \mathrm{t})$ was tested over $3 \frac{1}{2}$ years in a relatively sheltered area of sea off Denmark (Nissum Bredning) [KOF 06, CRU 08].

\subsubsection{Oscillating water column systems: type B}

\subsubsection{Basic principle}

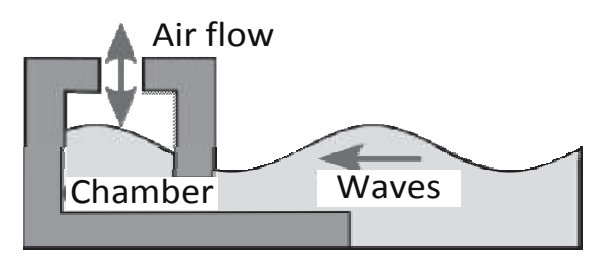

Figure 11.11. Principle of oscillating water column systems

Oscillating water column wave energy converters exploit changes in pressure in the air contained in a chamber (Figure 11.11). This chamber has a first opening which is continually submerged, so that the movements of the waves affect the column of water within the chamber. The alternating vertical movement of the internal free surface acts as a piston, creating first overpressure and then underpressure of the air trapped in the chamber. A second opening, in the open, channels the flow of air out. Thus the air is expelled and imbibed in turn, in accordance with the natural principle of "blowholes" which can be found on some rocky coasts. Air turbines, designed so that their direction of rotation is independent of the direction of the flow of air (impulse turbines, of Wells or Denniss-Auld turbines), coupled to electrical generators convert these alternating air flows into electricity.

The relatively high speed of these turbines means that "conventional" rotating generators with nominal rotation speeds of $1,500 \mathrm{rpm}$ or 3,000 rpm can be used, in the knowledge that the use of variable speed technology improves the efficiency of energy conversion in various sea states. The rotational kinetic energy stored by the moment of inertia of the rotating parts, which may be connected to an additional flywheel, can be used to smooth fluctuations of the incident mechanical power. The orders of magnitude of inertia $\left(\sim 100\right.$ to $\left.1,000 \mathrm{~kg} \cdot \mathrm{m}^{2}\right)$ and rotation speed $(\sim 1500 \mathrm{rpm})$ only allow for short-term adjustment of this kind. However, exploiting this energy involves being able to control the torque exerted by the generator and thus pilot it using an electrical power converter, either at the level of the rotor in a doubly-fed generator or at the stator in a full-power converter. The mechanicalelectrical energy conversion systems would be type 1 and type 2 (Figure 11.6) for this type of wave energy converter. 
The chamber may be situated on the coastline (onshore) or on a floating platform (offshore). It may be built of concrete (onshore) or steel (offshore), but its shape and proportions must be optimized so as to convert the maximum amount of wave energy possible. Indeed, the movement of the column of water, which exerts a hydrostatic restoring force, is a resonating mechanical oscillation, and therefore has a natural frequency, which at the design stage we try to adapt to the prevailing frequency of the waves on the site.

\subsubsection{Examples}

Many prototypes for oscillating water column systems have been built, from the mid-1980s onwards, primarily on the shoreline. We might cite the Kvaerner column, at Toftestallen in Norway, on the same site as the "Tapchan" (1985) (see Figure 11.12). With a peak power of $500 \mathrm{~kW}$, the prototype constructed had a captation surface (internal surface of the cavity) of $50 \mathrm{~m}^{2}$. The Wells air turbine was coupled to a synchronous electrical generator. The lower part of the column was built of concrete, the upper part of steel. The latter was swept away during a storm, although the concrete base remained. Reconstruction projects were drawn up, but the plans never came to fruition. Given the enormous and prohibitive civil engineering costs involved in building these types of systems, other prototypes were built in places where there were artificial dykes, particularly in India (Vizhinjam), Japan (Sakata), Portugal (Douro) or Spain (Mutriku).

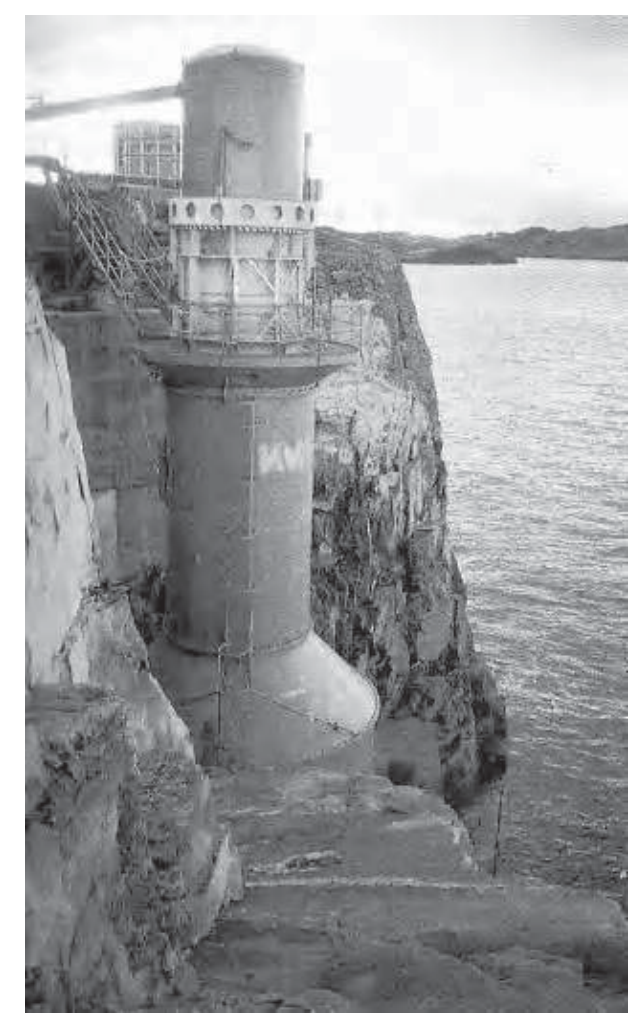

Figure 11.12. Kvaerner column in Norway [FAL 93] 


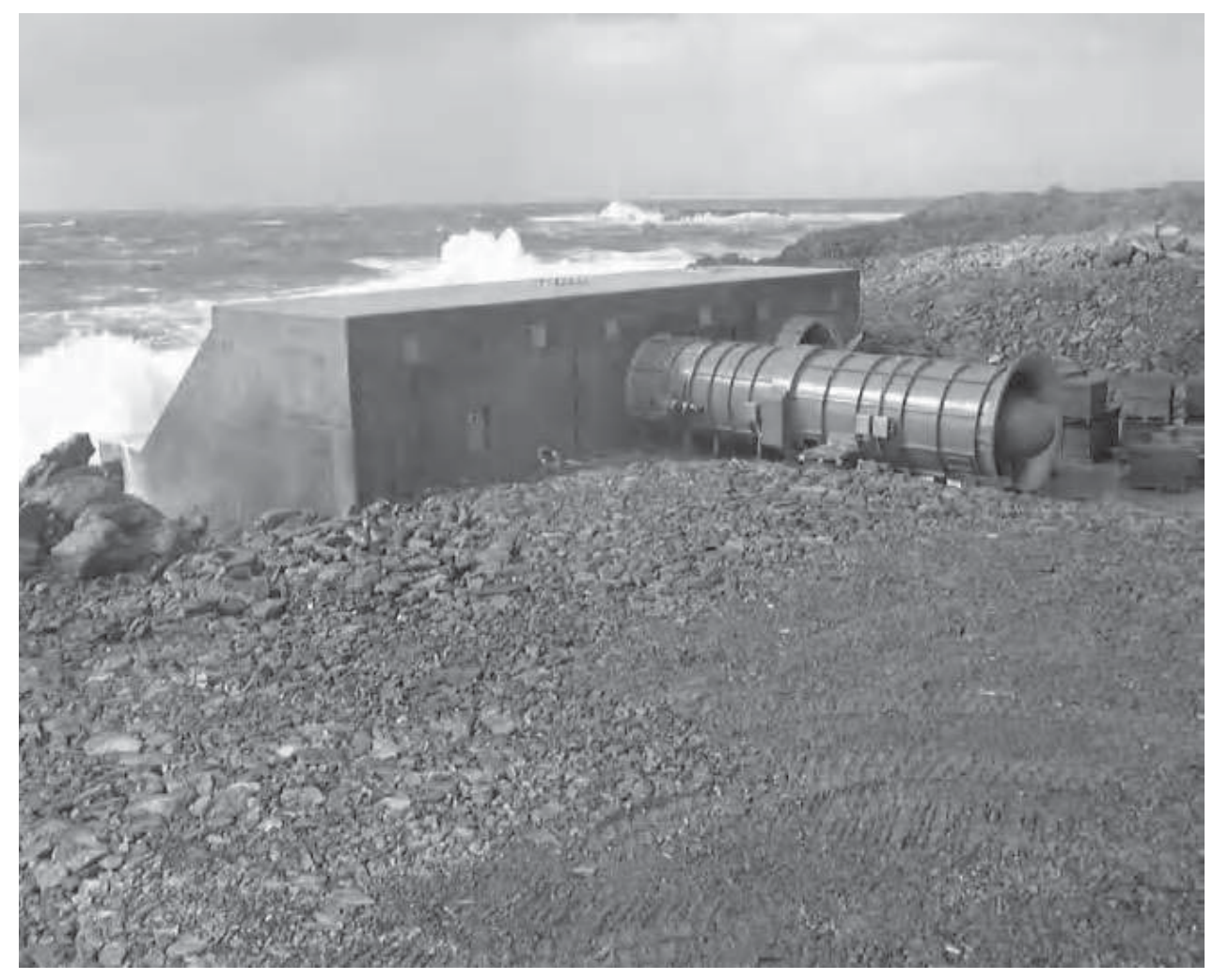

Figure 11.13. LIMPET plant in Scotland [BEL 02]

In the early 2000s, the LIMPET plant (Land Installed Marine Powered Energy Transformer) was built at Islay in Scotland (see Figure 11.13) and linked into Britain's electrical grid by the company Wavegen. An early prototype with a nominal power of $75 \mathrm{~kW}$ had been installed in 1991 on the same site. The subsequent, $500 \mathrm{~kW}$ version, is $21 \mathrm{~m}$ long and has a captation surface of $169 \mathrm{~m}^{2}$. It is divided into three caissons in the interests of better hydrodynamic adaptation, but also to relieve the strain on the structure of the chamber, built of Bi-steel, a highresistance composite material of steel and concrete.

Two Wells turbines turning in counter-rotation were driven by the flow of air. They were $2.6 \mathrm{~m}$ in diameter, and had a nominal speed of 1,050 rpm. Flywheels were used to stabilize their speed and thereby the production of electricity. The initial idea was to use wound-rotor induction machines whose rotoric resistance could be varied using thyristors to increase the range of operable speeds at a lesser cost, and a stator connected directly to the grid. However, Wavegen preferred to tolerate the additional cost of an electronic power converter, designed for full power, connected to the stator. Given that the wound-rotor machines had already been bought, they were used with a short-circuiting rotor [BEL 02]. With the resulting moment of inertia added by flywheels $\left(1,300 \mathrm{~kg} \cdot \mathrm{m}^{2}\right)$, the startup time of the turbogenerator was 14 minutes (motor startup was limited by the maximum current on the local grid, of $125 \mathrm{~A}$ ). 


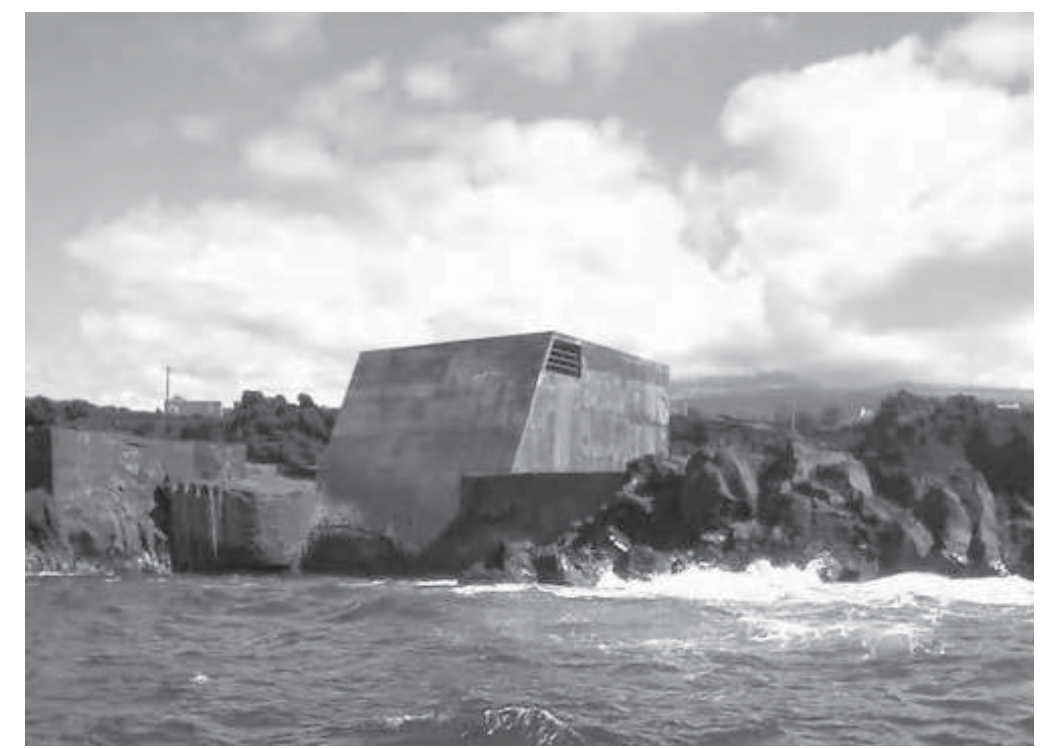

Figure 11.14. Plant on Pico in the Azores [NEU 07]

Just before the turn of the millennium, a similar plant was built on the isle of Pico in the Azores (Figure 11.14). It is a European pilot project, with a nominal power of $400 \mathrm{~kW}$ and a captation surface of $144 \mathrm{~m}^{2}$. First equipped with a fixedspeed Wells turbine, then with a variable speed turbine, it uses a wound-rotor doubly-fed induction generator. The machine has 4 pairs of poles (synchronous speed $750 \mathrm{rpm}$ ) and only functions in generator mode in conditions of hypersynchronous regime (unidirectional power converter, Figure 11.15) with a range of speed varying from 750 to $1,500 \mathrm{rpm}^{-1}$. The stator winding is designed for a nominal power of $200 \mathrm{~kW}$ as for the rotor winding and its electrical power converter, meaning the installation can convert a maximum power of $400 \mathrm{~kW}$ at 1,500 rpm.

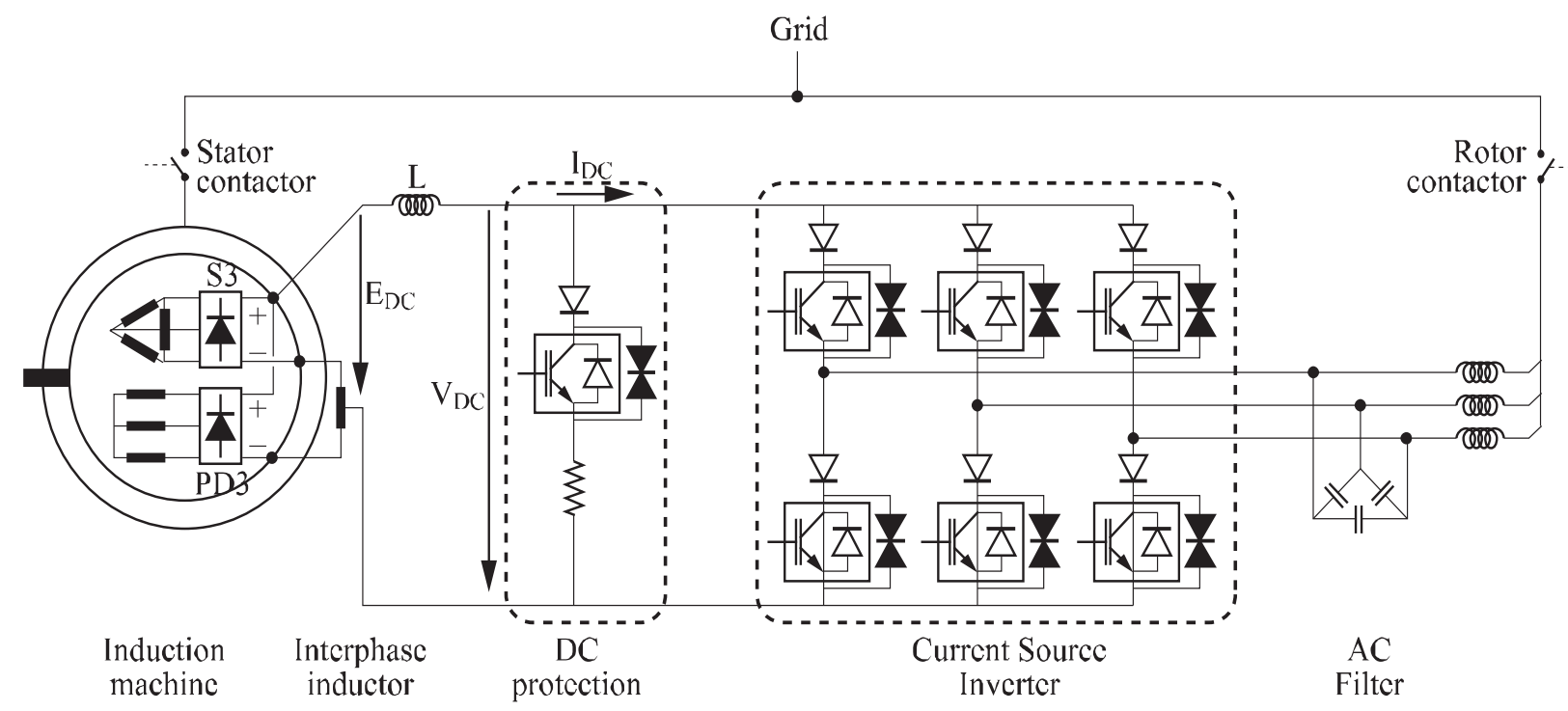

Figure 11.15. Electrical diagram of the energy generating system in the Pico power plant [RAM 99] 
Other oscillating water column systems have been designed to float, for offshore applications. Under the direction of Professor Yoshio Masuda, JAMSTEC (Japan Marine Science and Technology Center) in 1976 built an experimental craft, the Kaimei, $(80 \mathrm{~m} \times 12 \mathrm{~m})$ with four separate chambers to test a design at sea. Tests were carried out in 1978 and 1979. They went on to build the Mighty Whale (Figure 11.16), a $50 \mathrm{~m} \times 30 \mathrm{~m}$ floating prototype for a depth of $12 \mathrm{~m}$ and displacing $4830 \mathrm{t}$, which became operational in 1998. It had a total nominal power of $110 \mathrm{~kW}$. Three Wells turbines $11.7 \mathrm{~m}$ in diameter drove three induction generators $(1 \times 50 \mathrm{~kW}$ and 2 x $30 \mathrm{~kW})$ with variable speed (300-1,800 rpm).

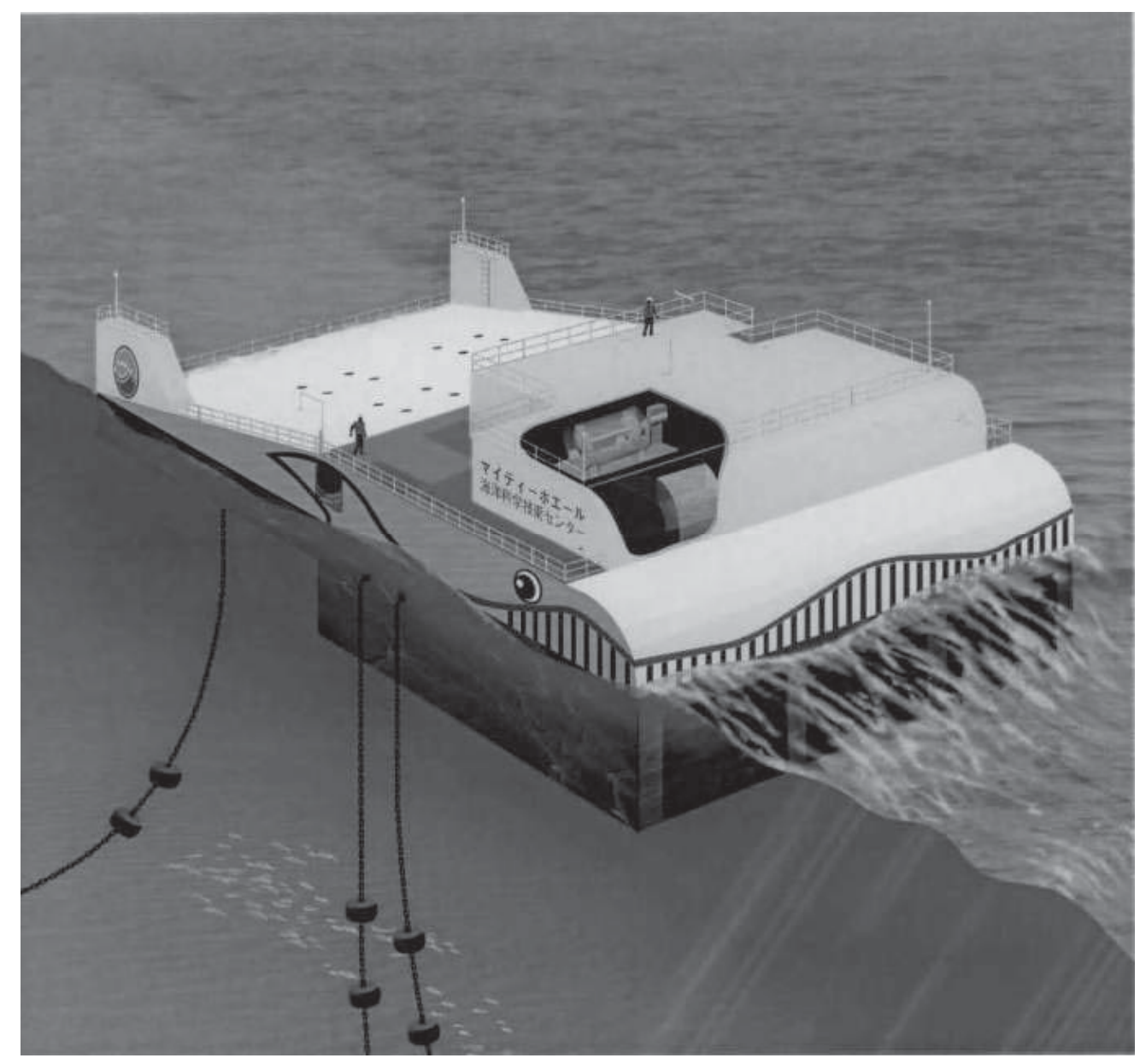

Figure 11.16. The Mighty Whale from Jamstec (source: JAMSTEC)

The Australian company Oceanlinx (known as Energetech until April 2007) installed an offshore oscillating water column system (Figure 11.17) with a patented variable-speed "Denniss-Auld" turbine. It is designed to provide both electricity with a maximum power of $1 \mathrm{MW}$ and desalinated water. This double means of production is very attractive for isolated sites such as islands. There are also a number of projects in the pipeline, particularly on the Hawaiian Islands. These floating devices can also be used as "breakwaters" to protect coastal sites such as ports or fish farms. 


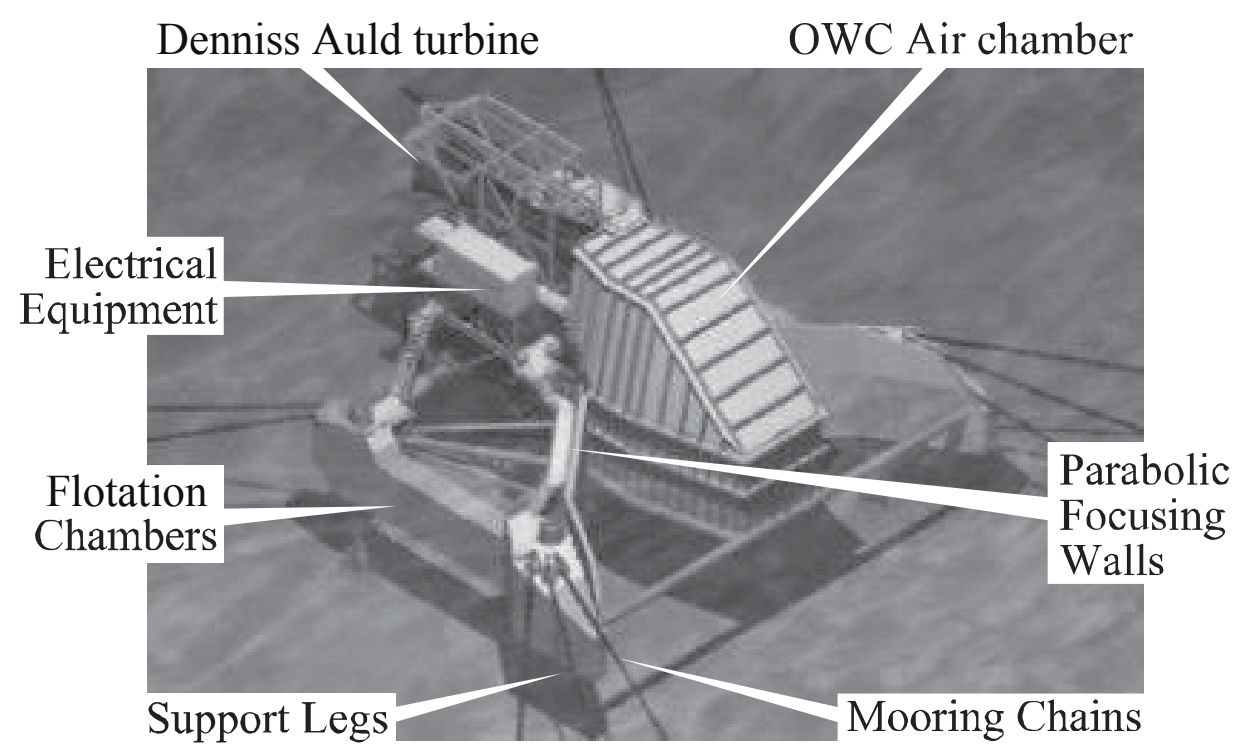

Figure 11.17. Oceanlinx system [PRE 04]

\subsubsection{Oscillating body systems: type C}

\subsubsection{Basic principle}

When an elongated floating body (such as a ship) is subject to the swell, it undergoes movements according to its 6 degrees of freedom: 3 in translation (surge, heave and sway) and 3 in rotation (pitch, roll and yaw). Surge, sway and heave respectively are the movements of translation in relation to the longitudinal axis, the transversal axis and the vertical axis. Roll, pitch and yaw are the movements of rotation in relation to the longitudinal, transversal and vertical axes respectively.

With these systems, the principle consists of using the swell to set one or more bodies in motion. The movements may be relative between two parts (internal reference, see Figure 11.18) or between a fixed part and a mobile part (external reference, see Figure 11.19). There are many technologies based on this principle. They can be classified according to the degree or degrees of freedom used. Thus, we distinguish:

- systems using one or several surging buoys;

- systems using pitch, either floating or bottom-anchored;

- systems combining heave and pitch;

- systems combining heave and yaw.

The movements obtained are slow and alternating. They are used to drive an energy conversion system which damps the movements. Owing to the low frequency of wave motion, the speeds of translation or rotation are low, and the 
forces needed to extract energy are very high. Mechanical energy is extracted at the speed of the waves, with no inherent means of upstream storage. Therefore, we shall call these systems direct wave energy converters (DWECs), although this qualifier must not be confused with that which might characterize the mechanical-electrical conversion system associated with the devices, which for its part may be direct or indirect.

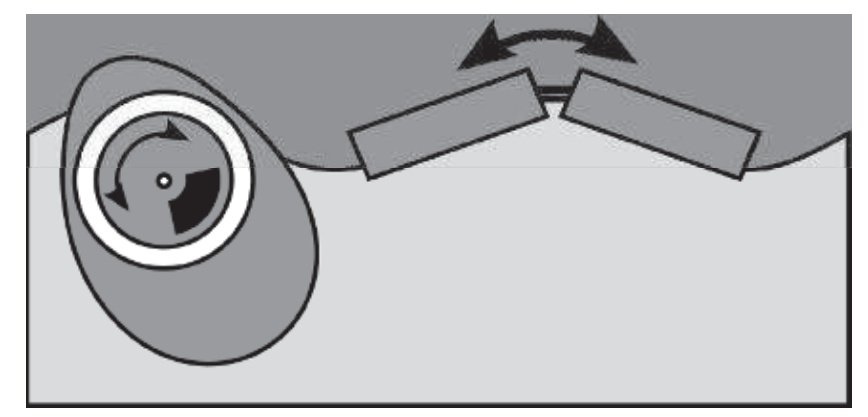

Figure 11.18. Oscillating systems with internal reference

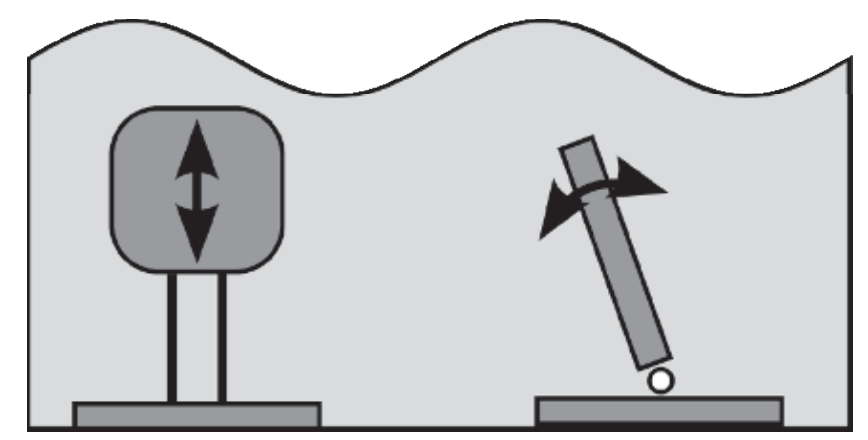

Figure 11.19. Oscillating systems with external reference

As regards the mechanical-electrical energy conversion system, when the force, linked to the damping of the movement or movements, is exerted by a hydro(oleo)pneumatic system, the conversion is said to be indirect (type 3, see Figure 11.6). Electricity is then generated via an energy conversion system which usually includes hydraulic rams (functioning as pumps), high-pressure/low-pressure accumulators, hydraulic motors, etc. and therefore can store a certain amount of intermediary energy (in the form of pneumatic pressure).

When the electrical generator itself absorbs the mechanical movement, with no intermediary conversion stage, we speak of direct drive mechanical-electrical energy conversion (type 5). A stage of mechanical adaptation of the movement may sometimes be preferable, in order to turn linear alternating motion into rotating alternating motion (type 4). The conversion is thus no longer direct, but similar to type 5 systems, the electrical power produced still does not benefit from upstream storage of energy. The electrical power is then extracted at the speed of the waves, 
and thus presents the same fluctuating characteristics as the waves themselves do (see section 11.4).

\subsubsection{Examples with indirect mechanical-electrical conversion system}

Aquamarine Power Ltd., founded in 2005, working with Queen's University in Belfast, developed the Oyster system (Figure 11.20) which belongs to the subcategory of "flaps" or "surging devices". These systems exploit the horizontal movement of the water, which is greater in shallow water. These devices are thus well adapted to nearshore zones. The Oyster system consists of a panel which oscillates with the waves; this panel is fixed to a base which is anchored on the bottom. Its movement pressurizes a fluid (water), using two pistons. This fluid feeds a hydroelectric (Pelton) turbine, located in a station on land, via an underwater hydraulic conduit [WHI 07]. If one of the two pistons breaks down, this reduction by half of the damping torque only leads to a $25 \%$ reduction in the power produced [HEN 10].

The first version, Oyster 1 , measuring $18 \times 11 \mathrm{~m}$ and with a nominal power of $315 \mathrm{~kW}$ in a sea state of $40 \mathrm{~kW} \cdot \mathrm{m}^{-1}$, was tested on the EMEC site (Scotland) and linked into the grid [COL 08]. The peak power of its second version, Oyster 2, is $800 \mathrm{~kW}$ (26 m x 16). It weighs 194 tons, to which we must add around 100 tons of ballast (seawater) enabling the hydrostatic recoil force of the oscillating panel to be adjusted. To date (September 2011), one Oyster 2 machine has been installed at Billia Croo in Scotland; there are plans to install a further two on the same site in the next few years, to create a farm with a nominal power of 2.4 MW total [CAM 10, AQU 11].

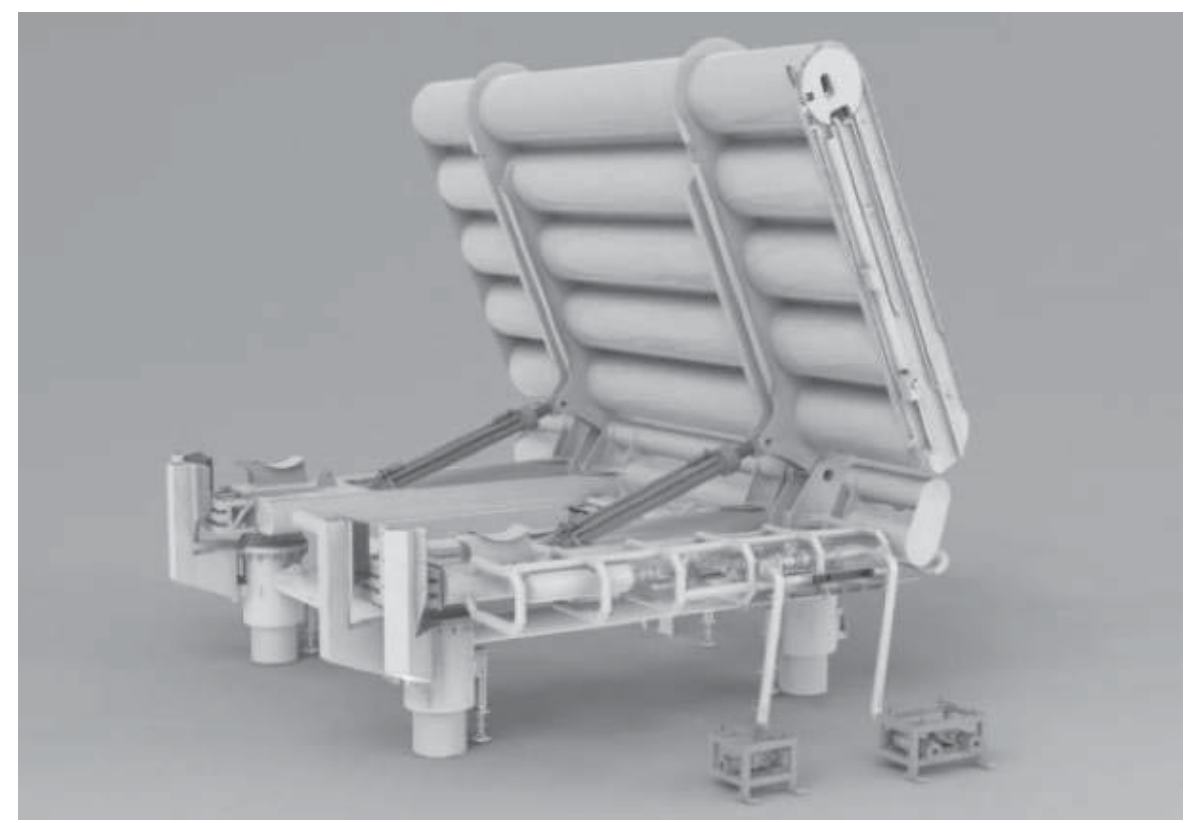

Figure 11.20. The Oyster system [CAM 10] 
A CETO (cylindrical energy transfer oscillator, see Figure 11.21) is what is known as a "point absorber", i.e. a surging system (which is subjected to vertical movements). This system, which is small in relation to the wave length of the incident swell (the buoy is around $7 \mathrm{~m}$ in diameter), is designed to be completely submerged and to compress water by its alternating movements. This pressurized water is transported to land via a network of channels, and some of it is used in an inverse osmoser to produce desalinated water and drive a Pelton turbine to produce electricity. EDF Energies Nouvelles, which in January 2008 gained the exclusive right to use this technology in the northern hemisphere and for the island of $\mathrm{La}$ Réunion (east of Madagascar), hopes to install 20-30 MW by 2015 on the shores of the island.

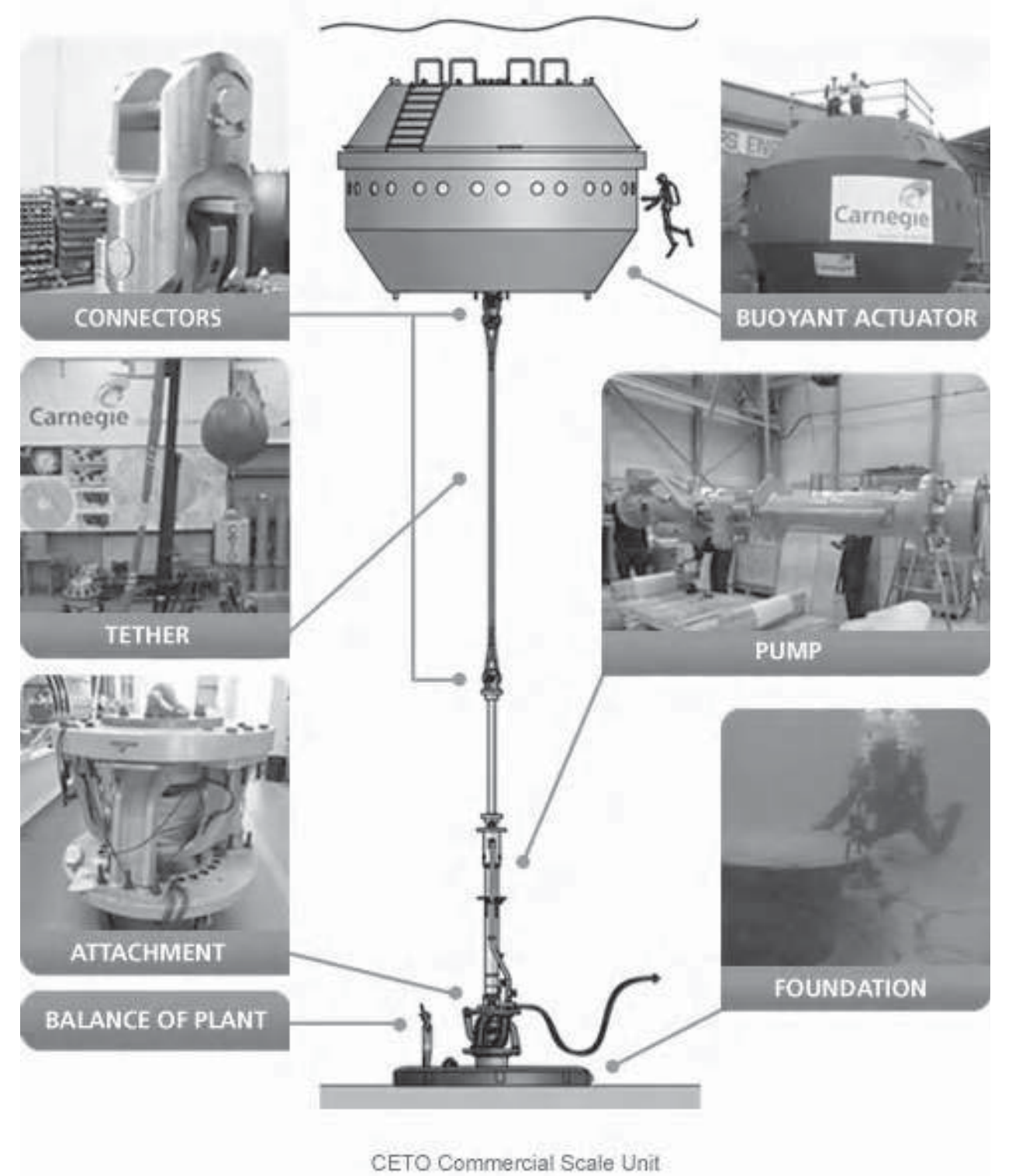

Figure 11.21. The CETO system [CAR 11] 
As for the Pelamis system, from Pelamis Wave Power Ltd., the moving bodies are cylinders $4 \mathrm{~m}$ in diameter linked by joints with two degrees of freedom (universal joint). The relative movements between the different parts are absorbed by hydraulic rams acting as pumps. The energy is stored in pneumatic accumulators (tanks filled with gas and put under pressure by oil from the hydraulic circuit). These high- and low-pressure accumulators mean that at a given sea state the hydraulic motors distributed through the system can be provided with an almost constant flow of fluid and therefore produce a relatively stable supply of electricity in spite of the fact that the resource is fundamentally fluctuating. It is also designed to shut down hydrodynamically under the influence of extreme waves and thereby avoid potential damage.

In its earliest version, named P1, six hydraulic motors distributed between three conversion modules (one for each joint), each drive a $125 \mathrm{~kW}$ induction generator. An oil-water heat exchanger is included to evacuate the excess power produced in high seas, or all of it if the connection to the electrical grid is lost. A $690 \mathrm{~V}$ alternating voltage bus runs through the system and feeds a step-up transformer. A network-side voltage of $11 \mathrm{kV}$ was chosen at the prototyping stage.


Figure 11.22. The Pelamis system (left: version P1 and right: P2) [PEL Ltd]

A farm of 3 Pelamis machines (version P1, see Figure 11.22) was installed in northern Portugal during the summer of 2008. The total installed power is therefore around 2.25 MW. Estimated annual production is $2.7 \mathrm{GWh}$ per $750 \mathrm{~kW}$ unit for an average annual resource of $55 \mathrm{~kW} / \mathrm{m}$, equivalent to 3,600 hours at full power. A chart of the annual electrical power produced depending on the sea state is shown in Figure 11.23. We can then deduce the annual productivity on a particular site using this chart and one of probability of occurrence of sea states. Many projects for farms of this type are currently being built, particularly in Scotland and Cornwall. 
Power period (Ppow, s)

\begin{tabular}{|c|c|c|c|c|c|c|c|c|c|c|c|c|c|c|c|c|c|}
\hline & 0 & 5 & 6.0 & 6.5 & .0 & 7.5 & .0 & 5 & .0 & .5 & 0.0 & 0.5 & 0 & 1.5 & 2.0 & 2.5 & \\
\hline 0.5 & empty & empty & mpty & empty & empty & ty: & npty & empty & empty & empty & empty & empty & mpty & empty & empty & npty & mpty \\
\hline 1.0 & empty & 22 & 29 & 34 & 37 & 38 & 38 & 37 & 35 & 32 & 29 & 26 & 23 & 21 & empty & empty & mpty \\
\hline 1.5 & 32 & 50 & 65 & 76 & 83 & 86 & 86 & 83 & 78 & 72 & 65 & 59 & 53 & 47 & 42 & 37 & 33 \\
\hline S & 57 & 88 & 115 & 136 & 148 & 153 & 152 & 147 & 138 & 127 & 116 & 104 & 93 & 83 & 74 & 66 & 59 \\
\hline & 89 & 138 & 180 & 212 & 231 & 238 & 238 & 230 & 216 & 199 & 181 & 163 & 146 & 130 & 116 & 103 & 92 \\
\hline & 129 & 198 & 260 & 305 & 332 & 340 & 332 & 315 & 292 & 266 & 240 & 219 & 210 & 188 & 167 & 149 & 132 \\
\hline & - & 270 & 354 & 415 & 438 & 440 & 324 & 404 & 377 & 362 & 326 & 292 & 260 & 230 & 215 & 202 & 180 \\
\hline 4.0 & - & - & 462 & 502 & 540 & 546 & 530 & 499 & 475 & 429 & 384 & 366 & 339 & 301 & 267 & 237 & 213 \\
\hline 4.5 & - & - & 544 & 635 & 642 & 648 & 628 & 590 & 562 & 528 & 473 & 432 & 382 & 356 & 338 & 300 & 266 \\
\hline 5.0 & - & - & - & 739 & 726 & 731 & 707 & 687 & 670 & 607 & 557 & 521 & 472 & 417 & 369 & 348 & 328 \\
\hline 5.5 & - & - & - & 750 & 750 & 750 & 750 & 750 & 737 & 667 & 658 & 586 & 530 & 496 & 446 & 395 & 355 \\
\hline$\overline{\sigma_{0}} 6.0$ & - & - & - & - & 750 & 750 & 750 & 750 & 750 & 750 & 711 & 633 & 619 & 558 & 512 & 470 & 415 \\
\hline 6.5 & - & - & - & - & 750 & 750 & 750 & 750 & 750 & 750 & 750 & 743 & 658 & 621 & 579 & 512 & 481 \\
\hline 7.0 & - & - & - & - & - & 750 & 750 & 750 & 750 & 750 & 750 & 750 & 750 & 676 & 613 & 584 & 525 \\
\hline 7.5 & - & - & - & - & - & - & 750 & 750 & 750 & 750 & 750 & 750 & 750 & 750 & 686 & 622 & 593 \\
\hline 8.0 & - & - & - & - & - & - & - & - & 750 & 750 & 750 & 750 & 750 & 750 & 750 & 690 & 625 \\
\hline
\end{tabular}

Figure 11.23. Chart of the electrical power of the Pelamis P1 [PEL]

In its commercial version P2, the dimensions of the Pelamis are slightly larger, with a diameter of $4 \mathrm{~m}$ and length of $180 \mathrm{~m}$. It has one extra joint, and thereby goes from 3 to 4 active joints, giving a total of 5 cylindrical parts. The nominal power, however, is the same. It weighs around 1,300 tons. A prototype of the P2 is currently being tested in the Orkney Islands (Figure 11.22).

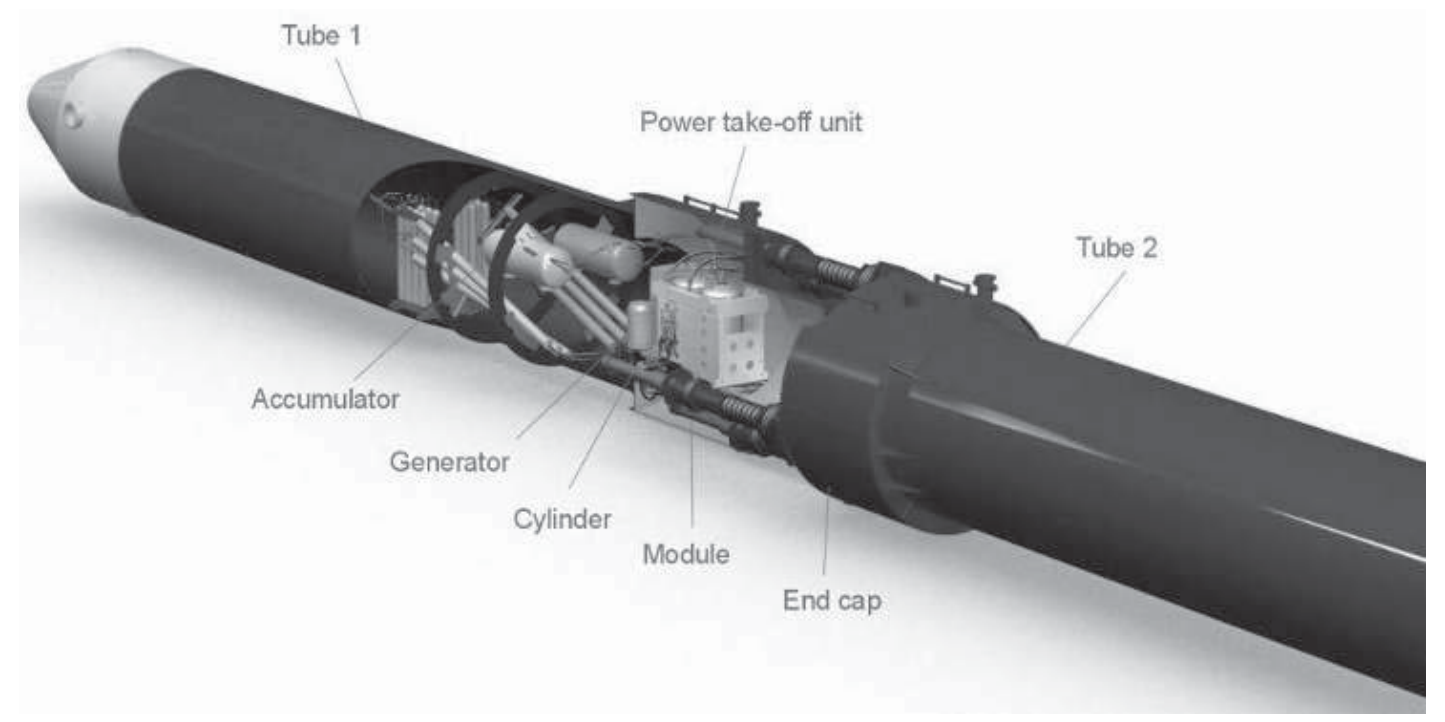

Figure 11.24. Detailed diagrammatic representation of a conversion module for a joint of the Pelamis P2 [PEL] 


\subsubsection{Hydrodynamic performance of wave energy converters: capture width and capture width ratio}

In harnessing energy from the waves, the capture width $B_{W}$ is defined as the relation of the power absorbed by the wave energy converter to the flow of energy transported by the waves per meter of wavefront, $P_{W}$.

$$
B_{W}=\frac{P_{a b s}}{P_{W}}
$$

This relation is homogeneous to a given length. It may be interpreted as the wavefront width of wave energy absorbed by the system.

By dividing the capture width by a relevant dimension $B$, we can obtain a measurement of the hydrodynamic performance $\eta_{1}$ :

$$
\eta_{1}=\frac{B_{W}}{B}=\frac{P_{a b s}}{P_{W} B}
$$

It can be interpreted as the primary efficiency of the system.

The choice of a pertinent dimension must be made according to the principle upon which the wave energy converter works. Most of the time, one uses the width of the system, i.e. its size perpendicular to the direction of propagation of the waves. This is not always so. For example, in the case of the Pelamis, the energy is absorbed as the waves pass along the length of the system, so the dimension used would be its length.

Let us note that $\eta_{1}$ is a measurement of the system's capacity to absorb wave energy, but not of the production of electricity. For this, we must take account of the losses incurred in the other components of the conversion system (mechanical interfaces, electromechanical converters and electronic power systems, electrical cables, possibly storage facilities, etc.).

Table 11.1, taken from [BAB 11], presents an overview of the hydrodynamic performances of the different categories of wave energy converters, according to the classification given by Falcão [FAL 10] (see Figure 11.5). It was compiled using data published in the existing literature.

We can see that the hydrodynamic performances can vary by a factor of 4 depending on the principle upon which the designs are founded. It can be said that on average, the hydrodynamic performance of modern wave energy converters is 
between 20 and 30\%. Typically, a wave energy converter could therefore absorb around a quarter of the wave energy to which it is exposed.

\begin{tabular}{|l|l|c|c|c|c|c|}
\hline \multicolumn{1}{|c|}{ Category } & Sub-category & $\begin{array}{c}\text { Average } \\
\text { hydrodynamic } \\
\text { performance }\end{array}$ & Min. & Max. & $\begin{array}{c}\text { Typical } \\
\text { size }\end{array}$ & $\begin{array}{c}\text { Reference } \\
\text { dimension }\end{array}$ \\
\hline $\begin{array}{l}\text { Oscillating } \\
\text { water } \\
\text { column }\end{array}$ & $33 \%$ & $20 \%$ & $45 \%$ & $30 \mathrm{~m}$ & Width \\
\hline $\begin{array}{l}\text { Overtopping } \\
\text { system }\end{array}$ & $\begin{array}{l}\text { Small heaving } \\
\text { buoy }\end{array}$ & $9 \%$ & $3 \%$ & $14 \%$ & $5 \mathrm{~m}$ & Width \\
\cline { 2 - 7 } & $\begin{array}{l}\text { Large heaving } \\
\text { buoy }\end{array}$ & $29 \%$ & $19 \%$ & $42 \%$ & $20 \mathrm{~m}$ & Width \\
\cline { 2 - 7 } & $\begin{array}{l}\text { Bottom-fixed } \\
\text { oscillating flaps } \\
\text { system }\end{array}$ & $41 \%$ & $25 \%$ & $65 \%$ & $20 \mathrm{~m}$ & Width \\
\cline { 2 - 7 } & $\begin{array}{l}\text { Floating } \\
\text { System } \\
\text { driven by } \\
\text { the waves } \\
\text { system }\end{array}$ & $20 \%$ & $14 \%$ & $36 \%$ & $25 \mathrm{~m}$ & Width \\
\cline { 2 - 7 } & $\begin{array}{l}\text { Floating system } \\
\text { combining surge/ } \\
\text { heave/pitch }\end{array}$ & $17 \%$ & $6 \%$ & $27 \%$ & $30 \mathrm{~m}$ & Width \\
\cline { 2 - 7 } & Heave/yaw & $5 \%$ & $7 \%$ & $150 \mathrm{~m}$ & Length \\
\hline
\end{tabular}

Table 11.1. Overview of hydrodynamic performances by categories of wave energy converters. Taken from [BAB 11]

\subsection{Direct wave energy converters with direct electromechanical conversion (type C5)}

As specified above, we call type C5 systems direct wave energy converters with direct electromechanical conversion, or more simply "direct drive". They have no energy conversion stage at which an inherent buffer storage facility could be controlled before the mechanical-electrical conversion, in order to smooth electrical production. The terminology is not yet set in stone in English literature. Sometimes we come across misuse of language, such as "direct drive wave energy converter" for systems which are direct wave energy converters but whose conversion system works at indirect drive (type C4) [AGA 08], but also imprecision with the term "direct wave energy converter" for wave energy converters with direct drive, which could therefore have been qualified as "direct drive wave energy converters" [LEI 06]. 
In summary, category C5 therefore excludes overtopping systems where the gravitational potential energy of the weight of water in the basin is exploited as a means of energy storage. It also precludes oscillating water column systems where the rotating kinetic energy stored in the rotating parts of the turbine can be used as a buffer storage system, or systems of bodies set in motion by the waves with a hydropneumatic conversion system, which use high- and low-pressure accumulators to regulate the pressure in the hydraulic circuits. These accumulators may act as energy storage. In all these wave energy converters, the primary energy (from the waves) is captured in a necessarily fluctuating manner, but the useful (electrical) energy provided is smoothed by an energy storage stage.

On the other hand, in direct drive wave energy converters, useful electrical power is produced at the rhythm of the incident wave energy, and is therefore fluctuating in the same way as the waves themselves are. This makes it more problematic a priori to link this kind of wave energy converters into the electrical grid than indirect wave energy converters.

There are, however, major advantages to a direct drive conversion system in the context of wave energy. A direct drive generator connected to an electronic power converter involves far fewer stages of energy conversion and moveable mechanical parts than a hydro-pneumatic system, for instance. Thus there is a substantial gain in the overall efficiency of conversion (from the wave to the grid).

In this context of a large number of mechanical cycles (nearly 100 million over the lifetime of the system), a source of fatigue, reliability is thus increased. The risks of a breakdown are largely diverted to the electrical conversion system (machine and converter) with "electrical"-type breakdowns which are easier to master and mitigate. Above all, it is the need for maintenance which is greatly reduced. This latter point is even more essential for offshore wave energy converters, which are installed in a highly stressful marine environment because the resource there is abundant, and for which the annual window for interventions is extremely restrictive (only a few days, at the most interesting sites from an energetic point of view). Indeed, it must be remembered that the machines are anchored off the coast, and that access to them will be extremely difficult for technicians. Minimizing preventative and curative maintenance is therefore a crucial criterion in developing these offshore technologies.

In addition, the possibilities for control offered by a direct drive energy conversion system are far greater. Indeed, with a hydro-pneumatic energy conversion system, it is difficult to precisely control the recuperative damping of the movement. This necessitates regulating the pressure levels in HP/LP accumulators in order to absorb it in a manner other than according to a dry friction-type law, or by latching/declutching the hydraulic circuit. With a direct energy conversion system, 
including an active electronic power converter, it is possible to control the damping torque at each moment and a priori to fulfill whatever damping law, on condition that the operating point sought remain within the operating limits of the machineconverter set.

Internationally, a few teams of researchers from the electrical engineering community work specifically on direct drive wave energy converters. The technological aspects constitute one of the primary, or strategic, problems of direct drive wave energy converters. We can point to the work of the University of Uppsala and the team led by M. Leijon [LEI 06], H. Poliner at Delft University and the Universities of Durham and Edinburgh with M.A. Mueller [MUE 02], and more recently Oregon State University with the team headed by T.K.A. Brekken and A. Von Jouanne.

In France, the Fluid Mechanics Laboratory (LMF in French) at the École Centrale de Nantes and the SATIE Laboratory at the École Normale Supérieure de Cachan have been working closely together for a number of years on an "allelectric" version of the SEAREV system (type C5 with a rotating direct-drive generator damping the motion of a pendulum system).

\subsubsection{Work at the Universities of Durham and Edinburgh (UK)}

It was Baker and Mueller who introduced the term "direct-drive wave energy converter" (DDWEC) [BAK 01] in the early 2000s. They define a DDWEC as a wave energy converter whose moving part is directly linked to that of an electrical generator. Since Baker and Mueller do not place oscillating water column systems, for which the generator is also directly linked to the moving part, in the category of DDWECs, a DDWEC is necessarily a type C5 wave energy converter according to the classification system put forward above.

They highlight the problems which wave energy converters with an indirect energy conversion system may encounter, with their multiple stages of conversion which lead to breakdowns but also to energy losses. According to them, the earliest engineers who worked on harnessing wave power had no choice at the time other than to design complex interfacing systems between a slow, alternating movement and rapid rotation so as to be able to use conventional electrical generators. The advent of an efficient and cost-effective electronic power system meant that solutions could be envisaged whereby the electric machine would be directly linked to an alternating movement. Thereby there would be fewer stages of conversion and a lesser probability of breakdown. However, the operating speed of the generator is then reduced significantly and this requires even greater forces to be applied. 
10 years later (2011), direct mechanical-electrical conversion is one of the most promising solutions in the context of wave energy.

Numerous studies have been carried out on designs for non-conventional linear generators aimed at directly converting wave energy. Baker's thesis [BAK 03] compares different topologies of linear machines: surface permanent magnet, transverse flow, Vernier reluctance magnet technology at the stator, and finally winding tubular technology in air.

More recently, following the work of McDonald [MCD 08a, MCD 08b] one the mechanical structure of low-speed, high-torque rotating generators for renewable energy systems, Hodgins et al [HOD 09] demonstrated the advantage of a modular structure for a winding machine in air. Known as C-GEN, each module is in the shape of a $\mathrm{C}$ with two opposing magnets facing one another. These modules can be assembled to create a complete rotating machine. They can also be assembled to form a linear generator, in which case the C-shaped modules are closed on themselves (see Figure 11.25) in order to mechanically relieve the structure of the forces of attraction. Experiments are being carried out to show the advantage for an application in wave energy conversion.

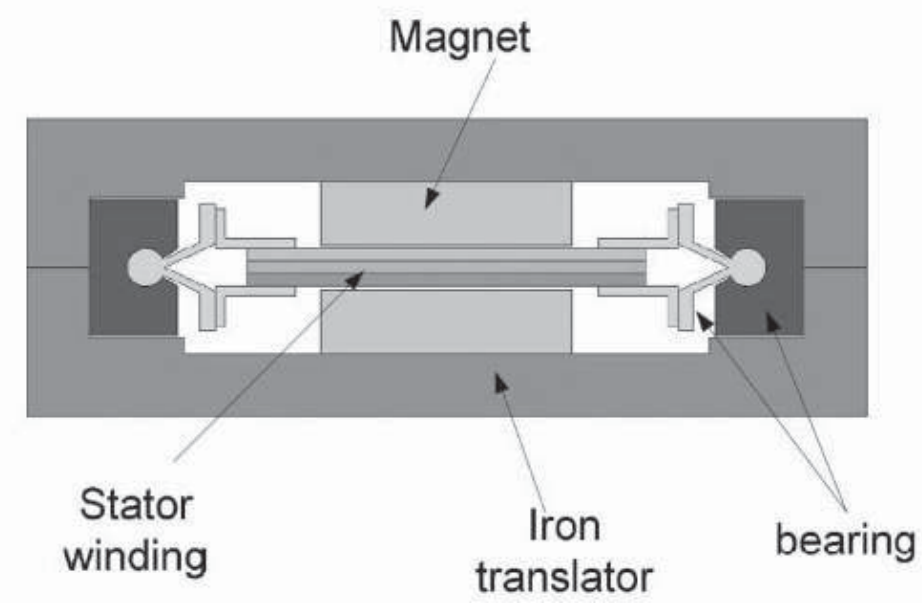

Figure 11.25. Diagram of a C-GEN module (frontal view) for a linear generator [HOD 10].

\subsubsection{Work at the University of Uppsala (Sweden)}

The earliest studies at the University of Uppsala led to the creation of SEABASED AB in 2001, which today is the parent company of the SEABASED Group. At its beginnings it was an innovation and patent holding company [BER 02]. This company then worked in close collaboration with Mats Leijon's team from the Angström Laboratory at the University of Uppsala, on a "point absorber"-type wave energy converter (Figure 11.26). A buoy is linked by a rope to the mover of a permanent magnet linear generator (the magnets are mounted on the 
mover). The buoy follows the movements of the waves and its oscillating movement is transferred to the mover of the generator. It is the weight of the generator, associated with a spring, which keeps the rope taut. The voltage generated is rectified using a diode bridge feeding a DC bus. The use of a resonating circuit to increase electrical production is also being studied [BOS 11].



Figure 11.26. Diagram of the principle of the wave energy converter being studied at the University of Uppsala [DAN 06]

\begin{tabular}{lc}
\hline \hline Main parameters of L1 & \\
\hline \hline Nominal power at $0.7 \mathrm{~m} / \mathrm{s}$ & $10 \mathrm{~kW}$ \\
Voltage, line-to-line, rms at $0.7 \mathrm{~m} / \mathrm{s}, V_{d}$ & $200 \mathrm{~V}$ \\
Generator resistance, $R_{G}$ & $0.44 \pm 1.5 \% \Omega$ \\
Generator inductance, $L_{S}$ & $11.7 \mathrm{mH}$ \\
Air gap & $3 \mathrm{~mm}$ \\
Size of magnet block & $6.5 \times 35 \times 100 \mathrm{~mm}^{3}$ \\
Pole width, $w_{p}$ & $50 \mathrm{~mm}$ \\
Number of stator sides & 4 \\
Vertical stator length & $1264 \mathrm{~mm}$ \\
Vertical translator length & $1867 \mathrm{~mm}$ \\
Translator resp. stator width & $400 \mathrm{~mm}$ \\
Translator weight & $1000 \mathrm{~kg}$ \\
\hline \hline
\end{tabular}

Figure 11.27. Main characteristics of the L1 prototype [BOS 11] 



Figure 11.28. Data collected on the Lysekil site from the L1 prototype feeding a resistive charge of 2.2 Ohms [LEI 08]

An experimental project (the Lysekil Project) began in 2002 with the aim, among others, of showing the feasibility of direct electrical conversion of wave energy. The first L1 prototype was installed in March 2006. The rope broke a few months after its installation, and was reconnected in March 2007. The linear generator, whose specifications are given in Figure 11.27, was then connected at the output to purely resistive charges. Experimental data are presented in Figure 11.28 for a delta-connected charge of $2.2 \Omega$. The first graph corresponds to the tension of the rope. Note the peaks at certain times, which correspond to the abutment of the moveable part onto end-stops formed by springs. Also, on the fourth graph, we can also see the typical fluctuation of the production of a direct drive wave energy converter over periods corresponding to half periods of the waves. 
In April 2007, the generator was connected to a DC charge, made up of an array of supercapacitors and a resistive charge by way of a diode rectifier (see Figure 11.29) [BOS 09, BOS 10]. The total capacity of the array of supercapacitors is 12.17 Farad (F). The array is made up of twelve Maxwell modules in a row (voltage/nominal capacitance $48 \mathrm{~V} / 160 \mathrm{~F}$ ) which represents a nominal power of around $600 \mathrm{Wh}$. The generator then supplies only when the electromotive force (EMF) reaches the same level as the voltage in the DC bus and therefore when the speed is high enough. Consequently, the damping thus obtained is highly nonlinear.

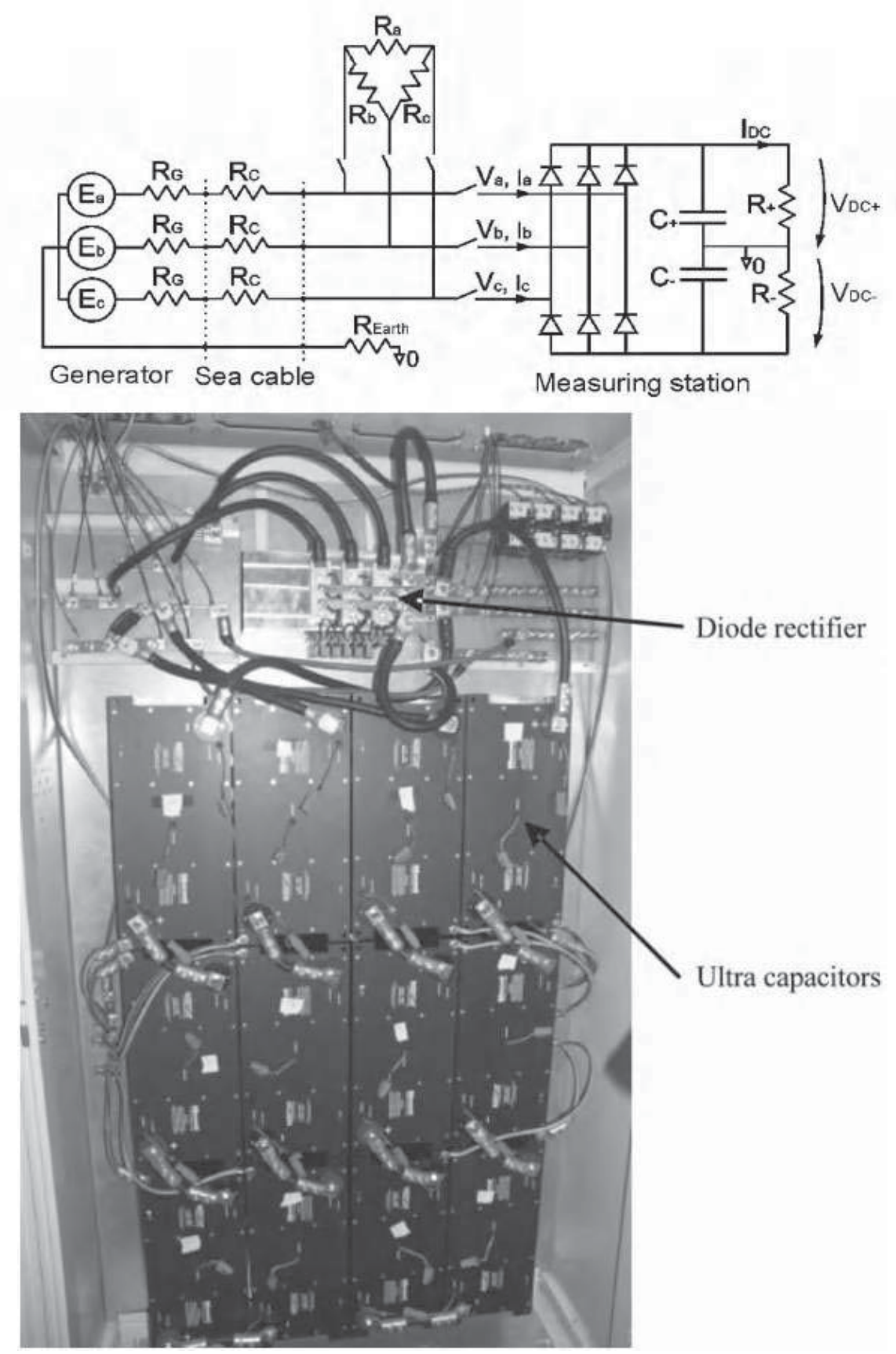

Figure 11.29. Redress setup put in place on the L1 prototype [BOS 10] (left) and array of supercapacitor modules installed in a measuring station on land [BOS 09] 


\subsubsection{Work at the Delft University of Technology (Netherlands)}

At the Delft University of Technology, H. Polinder researched and designed a linear generator using surface permanent magnets for the AWS system (Archimedes Wave Swing) [POL 00, POL 02, POL 04]. The original idea ${ }^{2}$ of the AWS consisted of exploiting the vertical heave component of the waves using a submerged piston. A production unit was made up of a cylindrical piston, the moveable part of which, under the influence of the waves, slid along another cylindrical part anchored to the seabed (see Figure 11.30). The moving piston directly drove a linear electrical generator.



Figure 11.30. Principle on which the AWS works [POL 05a]
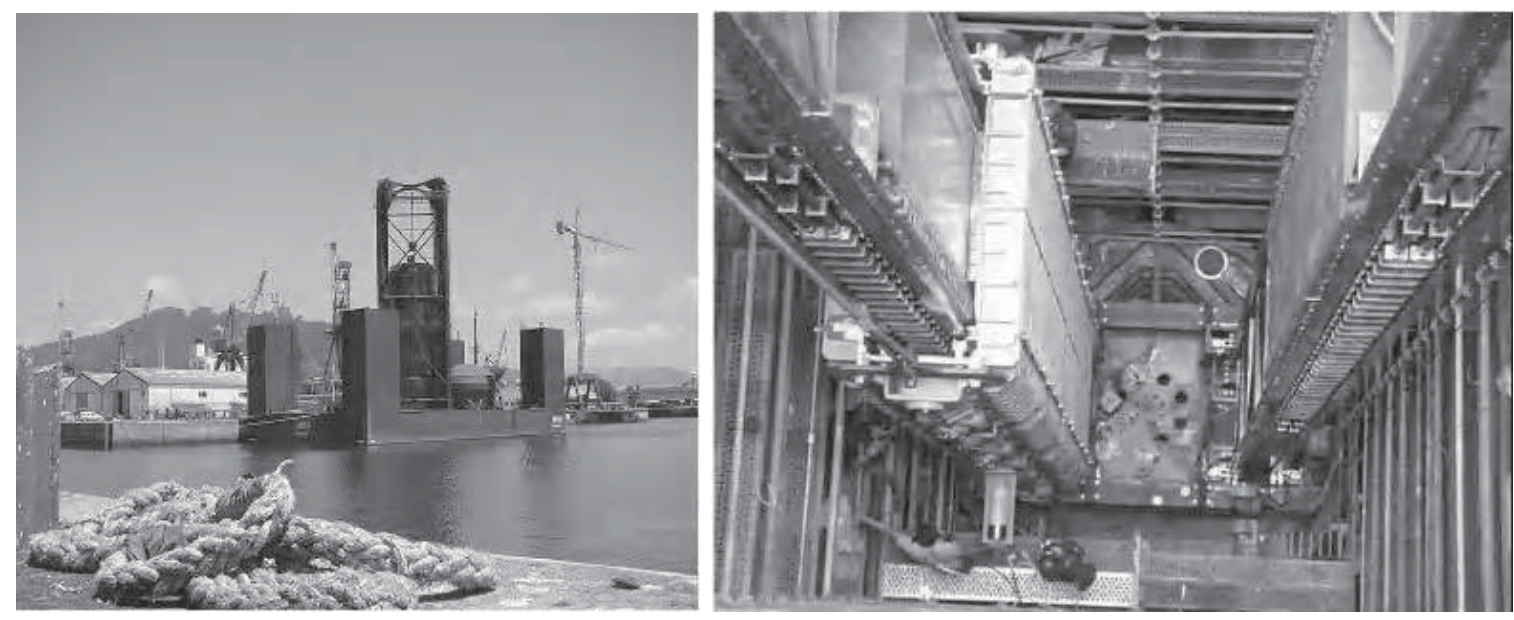

Figure 11.31. Left: the pilot AWS prototype before it was submerged [POL 04]. Right: the permanent magnet linear generator. The static parts (windings) are on the outside. The two moveable parts with the magnets on them are located on the left-hand side (light section) [POL 07]

2 The AWS-III system currently being developed by AWS Ocean Energy is a far cry from the first design, which was developed by Teamwork Technology. 
The pilot version of the AWS, tested in 2004 off the coast of Portugal, was equipped with a generator designed for a peak power of $2 \mathrm{MW}$ and a nominal power of $1 \mathrm{MW}$ (nominal speed: $7 \mathrm{~m}$ and $2.2 \mathrm{~m} . \mathrm{s}^{-1}$ ). The piston was $9 \mathrm{~m}$ in diameter and $20 \mathrm{~m}$ in height. The total weight of this test version reached 1,700 tons, to which 5,000 tons of ballast (sand) were added. The estimated annual power production was $1.64 \mathrm{GWh}$ on the pilot site in Portugal, which is equivalent to 1,640 hours/year at nominal power. The linear generator was divided into two identical parts as can be seen in Figure 11.31. Each part was made up of a double-sided mover and therefore double-sided stator so as to compensate the normal forces of attraction and relieve the strain on the mechanical structure.

\subsubsection{The SEAREV wave energy converter (CNRS, Ecole Centrale de Nantes, Ecole Normale Supérieure de Cachan)}

The principle of the SEAREV wave energy converter was developed in the Fluid Mechanics Laboratory (LMF) at the École Centrale de Nantes. Since 2004, that lab has been collaborating with the SATIE Laboratory at the École Normale Supérieure de Cachan (Brittany), studying an electromechanical conversion solution made up of a direct drive electrical generator connected to an electrical converter, instead of the oleo-pneumatic solution initially envisaged [RUE 07, AUB 11].

The SEAREV falls into the categories of oscillating bodies systems (type $C$ ). It is made up of a closed float set in motion by the swell. Inside it, a pendular wheel (with excentric mass) oscillates in relation to the float. In the all-electric version (type C5), a direct-drive electrical generator (e.g. a permanent magnet synchronous machine) is used to convert the mechanical energy from the pendular wheel into electricity and thus damps the relative movement between the float and the wheel (Figure 11.32).

This system has some original characteristics which set it apart from other wave energy converters:

- All the moving parts, all the technological components and other parts which are vulnerable to the marine environment are sheltered inside a completely closed float. This is a definite advantage as compared with systems in which the joints between the different moving parts (axles, sliders, etc.) are exposed to the influence of the sea (corrosion, biofouling, etc.).

- The pendular wheel pivots freely around its axis of rotation. No mechanical end-stops limit the amplitude of the movement. The system is therefore less susceptible to extreme sea states. This characteristic also allows us to level the power converted at a certain value when the rotation becomes particularly rapid, by decreasing the torque thereby allowing the wheel to gain speed without the risk of 
damage to the system. This capacity is not possible in translation-based systems (surging, for example) for which means of limiting the range of movement must be put in place (springs, dampers, stops, etc.).

- Thus, an internal reference system allows the use of slack (rather than taut) mooring lines. Tidal variations in sea level therefore have no effect on the system's operation.

- The design enables a direct drive rotating electrical generator to be used. Connected to an electronic power converter, this conversion system facilitates almost instantaneous control of the damping torque. It is therefore far simpler to implement advanced damping control than with an oleo-pneumatic system.



Figure 11.32. Diagram of the principle of the SEAREV system in its all-electric version

To date (2011), only one prototype on a 1/12 scale has been able to actually carry out electromechanical energy conversion, as other smaller models were aimed at testing seaworthiness and the integrity of the moorings. The geometry of a fullscale system is therefore not yet finalized, but we would be within reason to give the following approximate values: dimensions of $30 \mathrm{~m} \times 10 \mathrm{~m}$, a displacement of around 2,000 tons (200 tons for the body of the float, 300 tons for the pendulum flywheel, the rest being ballast, essentially made up of seawater), enabling the production of around $600 \mathrm{~kW}$ maximum (average power at the most powerful sea state). The average annual power depends heavily on the wave energy resource at the installation site. In such an electrical conversion system, the instantaneous power can be maintained at a set value (called leveling power) using an instantaneous 
control of the damping torque. Its final value will result from a trade-off between the cost of the conversion system (directly linked to its peak power) and energetic productivity (which increases with the leveling power value).

\subsection{Fluctuations of power produced by wave energy converters}

The study of fluctuations in the power produced by wave energy converters seems to constitute a fairly recent scientific problem, despite the fact that certain authors raised the question twenty-odd years ago. Take, for example [SAL 89]: "[...] The combination of 64 separate devices [...] would still be unacceptable input for a small island network. However about one hundred seconds of storage will produce a completely steady output from a single device in any typical wave spectrum". This "recipe", which is certainly pertinent, may result from the author's experience or intuition, but was not backed up at the time by a more in-depth analysis. In order to clarify our ideas about the need to deal with this problem in the case of production by wave energy converters, we have compiled a list based on existing literature, of a number of profiles, measured on site or simulated, of the power produced by different wave energy converters. Figures 11.33 to 11.39 show such profiles. The first examples (Figures 11.33 to 11.35) relate to oscillating water column systems (type B1). Thanks to the rotating kinetic energy stored in the continuously rotating parts, these systems can produce a relatively constant power supply in comparison to the incident pneumatic power. This means of storage must, however, be controlled in order to provide more effective smoothing.



Figure 11.33. OWC: Example of a profile of the power produced by the LIMPET plant [ALC 01] (the power becomes negative at certain points, probably in order to maintain a minimum speed value during a calm period) 


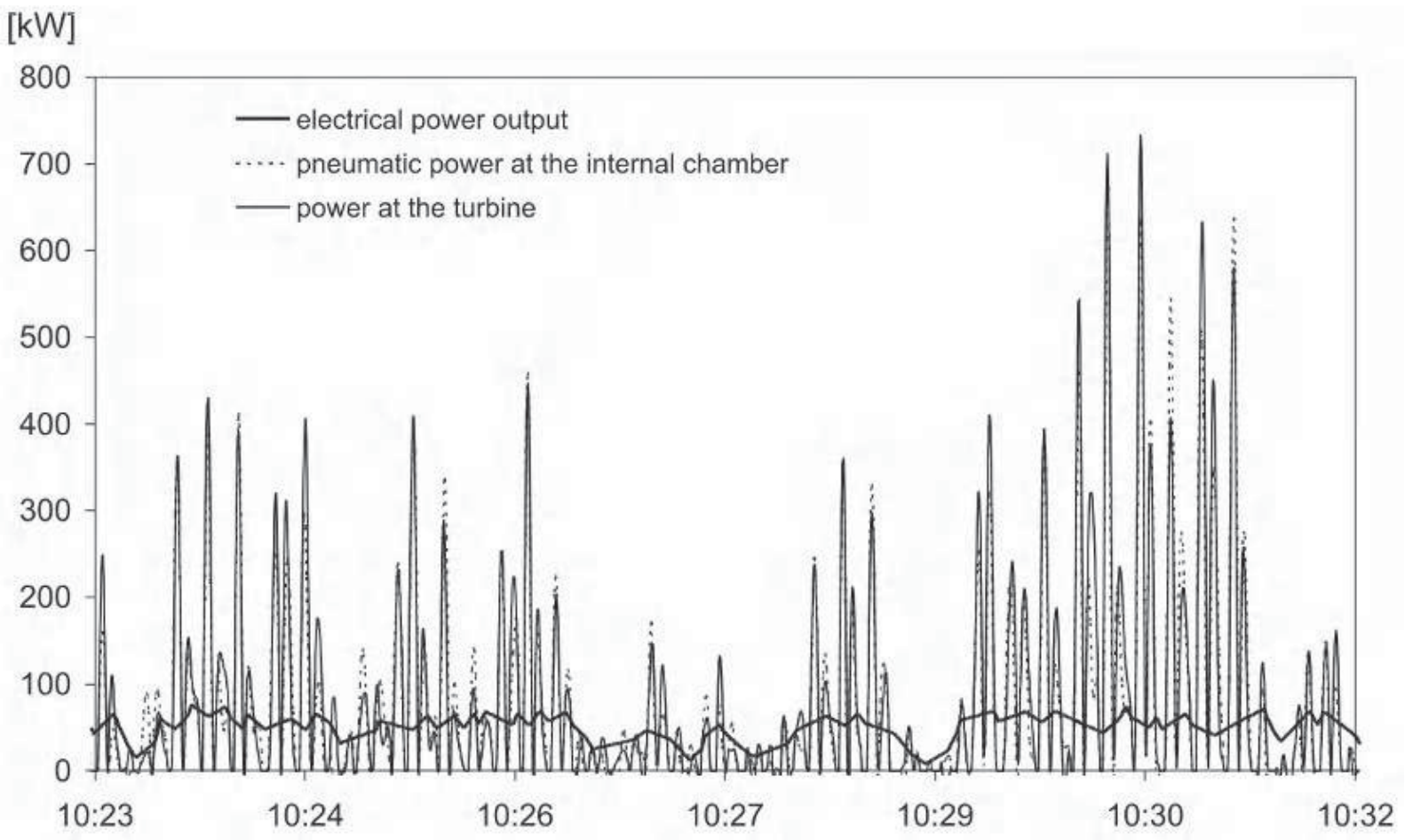

Figure 11.34. OWC: Example of a profile of the power produced by the Pico plant. The moment of inertia of the rotating parts is used to smooth the pneumatic power and incident mechanical power [CRU 08]
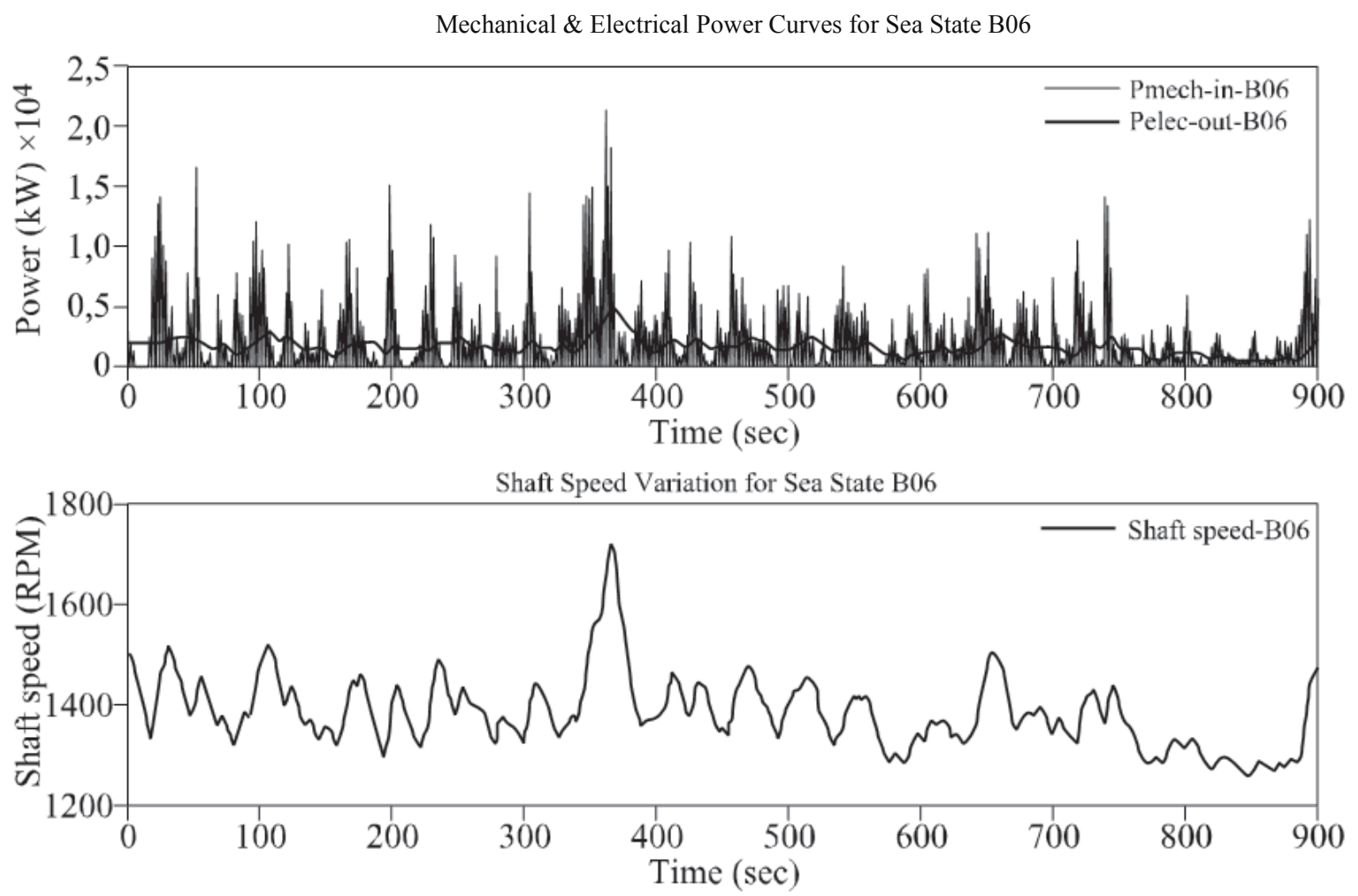

Figure 11.35. OWC: Simulated profiles of the incident mechanical power and electrical power generated by an oscillating water column emulator and the speed of rotation of the turbine (sea state $H=m, T_{p}=7.5 \mathrm{~s}$ ) [DUQ 09] 
In another category, the Pelamis (type C3) is an example of a direct wave energy converter with an indirect electrical conversion system including hydropneumatic accumulators which absorb the incident power. The electrical power produced (Figure 11.36) is therefore highly smoothed. In addition, the conversion modules distributed along the entire length of the Pelamis give rise to a proliferation effect which also contributes to smoothing the electrical power.
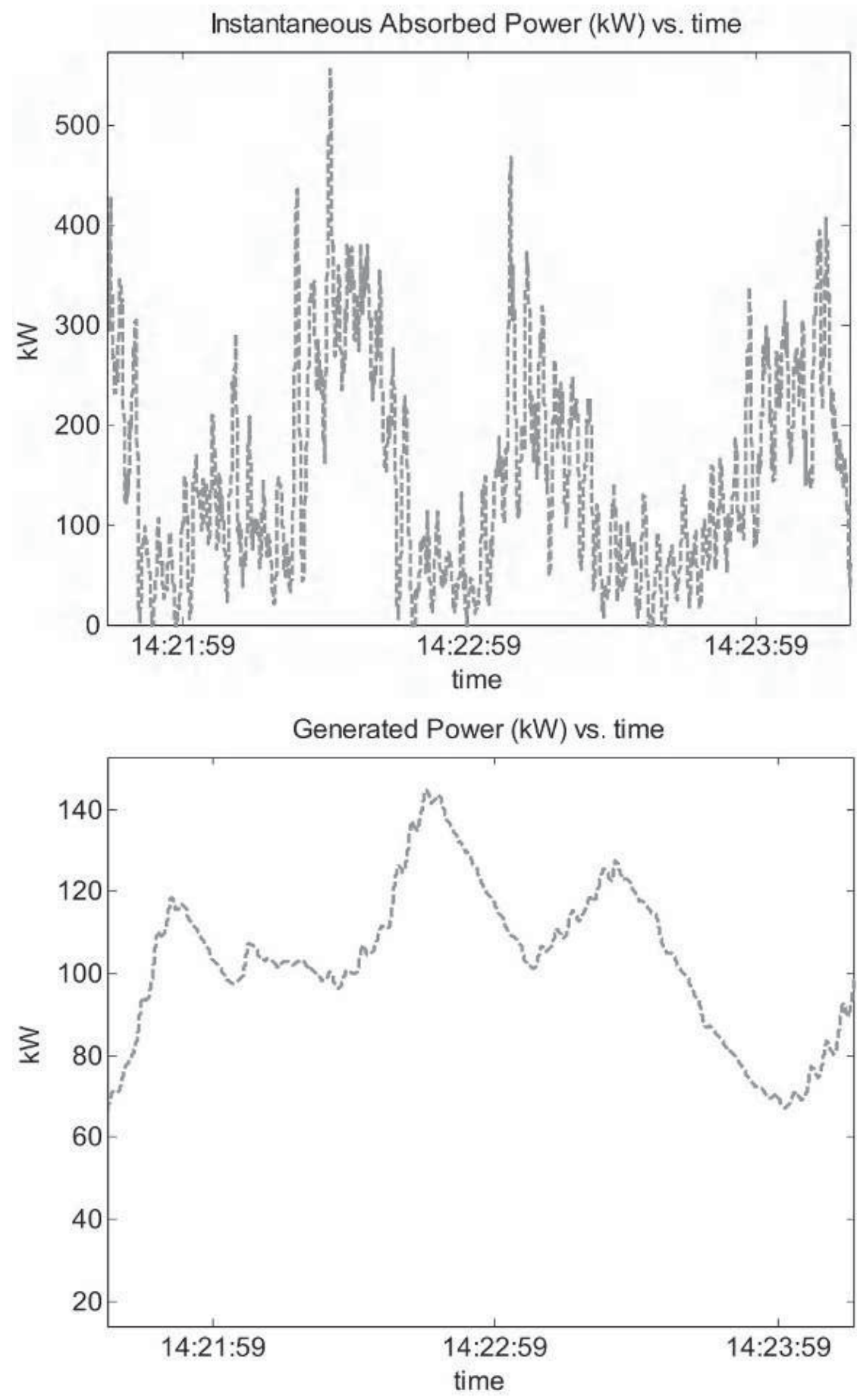

Figure 11.36. Profiles of measured incident hydraulic power and electrical power produced by the Pelamis prototype on 08/07/2007 [CRU 08] 
AWS (see Figure 11.37), Seabased (see Figure 11.28) and SEAREV (see Figure 11.38) provide an electrical power whose fluctuations reflect those of the incident waves precisely (the frequency of pulsation of the electrical power is equal to double the prevailing frequency of the waves). For these direct drive wave energy converters, the electrical power produced can only be smoothed using an energy storage system. The technology which appears to be the best adapted to on-board storage is supercapacitors. Short-term smoothing does not require a large amount of energy to be stored, but the power needed is significant (specific discharge time of $\sim 10 \mathrm{~s}$, which corresponds to the typical period of the waves) and the cycling capability must be high. In [AUB 10], a preliminary study of design with ageing taken into account shows the economic feasibility over the lifecycle of such a storage system applied to the SEAREV wave energy converter. If a stationary storage system is envisaged (on land, for example), storage using an inertia flywheel is another technological means which might be considered.



Figure 11.37. DWEC: Profile of measured electrical power generated by the AWS at a resistive charge of $2.75 \Omega$ [CRU 08$]$

Energy storage is thus one way of smoothing the electrical production of a wave energy converter. However, aggregating the individual production from several wave energy converters distributed in a farm is another. On the scale of a farm of wave energy converters spread out across several $\mathrm{km}^{2}$ of ocean, this strategy delivers "smoother" overall production than each individual profile. Indeed, besides the spatial dispersion of the production units, the frequential components of the swell are propagated at different speeds depending on the ratio of dispersion of gravity waves. Combined these two effects enable the dispersion (standard 
deviation) of the power produced to be maintained, in accordance with a law of $\sqrt{ } N$ where $N$ is the number of wave energy converters.

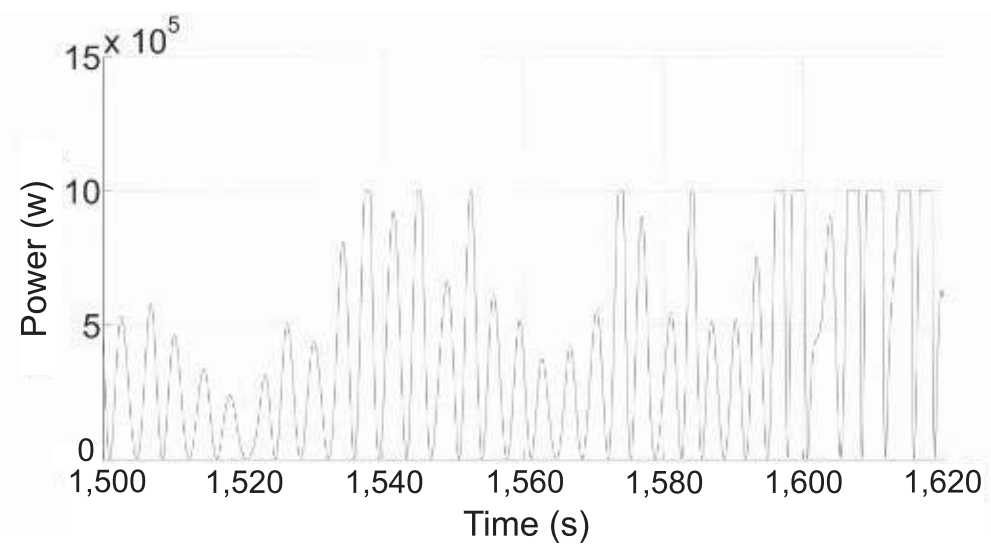

Figure 11.38. DWEC: Simulated example of a profile (taken from 2 minutes over a total duration of 1 hour) of the electrical power generated by an "all-electric" SEAREV device, with a sea state $\left(H_{s}=3 \mathrm{~m}, T_{p}=9.5 \mathrm{~s}\right)$ with a clipping power of $1 \mathrm{MW}$

An example is shown in Figure 11.39, of the results of a simulation [TIS 08] of the power produced by a farm of 7 SEAREV units whose relative disposition has been optimized. The different units are here considered to be hydrodynamically independent.



Figure 11.39. Profile of the power produced by a single SEAREV unit (in gray); and profile of the power produced by a farm of 7 SEAREVs (divided by 7) (in black). The average power produced per unit is indicated by the horizontal straight line.

Sea state considered: $9 \mathrm{~s}, 2.5 \mathrm{~m}$ [TIS 08] 


\subsection{Bibliography}

[AGA 08] Agamloh E.B., Wallace A., Von Jouanne A., "A novel direct-drive ocean wave energy extraction concept with contact-less force transmission system", Renewable Energy, vol. 33, pp. 520-529, March 2008.

[ALC 01] AlCORN R., BEATtie W., "Power quality assessment from the LIMPET WavePower Station", Proceedings of the $11^{\text {th }}$ International Offshore and Polar Engineering Conference, 2001, p. 17-22.

[AQU 11] AQUAMARINE POWER, http://www.aquamarinepower.com, September 2011.

[AuB 10] Aubry J., Bydlowski P., Multon B., Ben Ahmed H., Borgarino B., "Energy storage system sizing for smoothing power generation of direct wave energy converters",

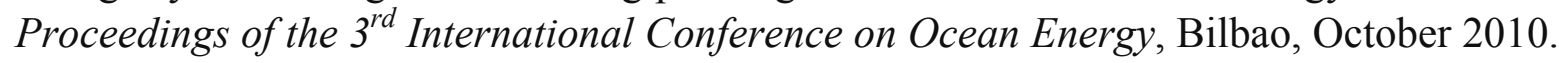

[BAB 11] BABARIT J., HALS J., "On the maximum and actual capture width ratio of wave energy converters", Abstract accepted for publication in Proc. of the $9^{\text {th }}$ European Wave and Tidal Energy Conference, Southampton, 5-9 September 2011.

[BAK 03] BAKER N.J., Linear generators for direct drive marine renewable energy converters, Durham University, PhD Thesis, 2003.

[BAK 01] BAKer N.J,. Mueller M.A., "Direct drive wave energy converters", Revue des Energies Renouvelables, vol. 4, p. 1-7, 2001.

[BEL 02] Queens University of Belfast, Islay Limpet Wave Power Plant, Publishable report, 2002.

[BER 02] BERNHOFF H., LEIJON M., A wave-power unit and the use of a wave-power unit for production of electric power, a method of generating electric power and a system of components for manufacturing a linear generator for a wave-power unit, Patent WO/2003/058055, Swedish Seabased Energy AB, 2002.

[BOS 09] Bostrom C., Lejerskog E., Stalberg M., Thorburn K., Leijon M., "Experimental results of rectification and filtration from an offshore wave energy system", Renewable Energy, vol. 34, pp. 1381-1387, May 2009.

[BOS 10] Bostrom C., Lejerskog E., Tyrberg S., Svensson O., Waters R., Savin A., BOLUND B., ERIKSSON M., LEIJON M., "Experimental results from an offshore wave energy converter", Journal of Offshore Mechanics and Arctic Engineering, vol. 132, 2010 .

[BOS 11] Bostrom C., Electrical systems for wave energy conversion, $\mathrm{PhD}$ Thesis, University of Uppsala, 2011.

[CAM 10] Cameron L., Doherty R., Henry A., Doherty K., Hoff J.V., Kaye D., NAYlor D., Bourdier S., WhitTAKer T., "Design of the next generation of the Oyster wave energy converter", $3^{\text {rd }}$ International Conference on Ocean Energy, Bilbao, pp. 1-12, 2010 .

[CAR 11] CARNEGIE WAVE ENERGY LiMITED, http://www.carnegiecorp.com.au/, April 2011. 
[Clé 02] Clément A.H., McCullen P., Falcao A.F., Fiorentino A., Gardner F., Hammarlund K., Lemonis G., Lewis T., Nielsen K., Petroncini S., Pontes M.T., SCHILD P., SJÖSTRÖM B.O., SORENSEN H.C., ThORPE T., "Wave energy in europe: current status and perspectives", Renewable \& Sustainable Energy Reviews, vol. 6, no. 5, pp. 405-431, 2002.

[COL 08] Collier D., Whittaker T., Crowley M., "The construction of Oyster a nearshore surging wave energy converter", $2^{\text {nd }}$ International Conference on Ocean Energy, Brest: 2008.

[CRU 08] CRUz J., Ocean Wave Energy: Current Status and Future Perspectives, Springer Verlag, 2008.

[DAN 06] DANIELSSON O., Wave energy conversion. linear synchronous permanent magnet generator, PhD Thesis, University of Uppsala, 2006

[DRE 09] Drew B., Plummer A R., Sahinkaya M.N., "A review of wave energy converter technology", Proceedings of the Institution of Mechanical Engineers, Part A: Journal of Power and Energy, vol. 223, pp. 887-902, December 2009.

[DUQ 09] Duquette J., O’Sullivan D.L., Ceballos S., Alcorn R., "Design and construction of an experimental wave energy device emulator test rig", $8^{\text {th }}$ European Wave and Tidal Energy Conference, Uppsala: 2009, pp. 443-452.

[FAL 10] DE O. FALCAO A.F, "Wave energy utilization: a review of the technologies", Renewable and Sustainable Energy Reviews, vol. 14, pp 899-918, 2010.

[FAL 93] FALNES J., "Research and development in ocean-wave energy in Norway", International Symposium on Ocean Energy Development, Muroran, pp. 27-39, 1993.

[FOL 09] FOLLEY M. WhitTAKER T.J.T., "Analysis of the nearshore wave energy resource”, Renewable Energy, vol. 34, pp. 1709-1715, July 2009.

[GUY 01] GuYOn É., Hulin J.-P., PetiT L., Hydrodynamique physique, EDP Sciences, 2001.

[HEN 10] Henry A., Doherty K., CAmeron L., Whittaker T., Doherty R., “Advances in the design of the Oyster Wave Energy Converter", Royal Institution of Naval Architects (RINA) Marine and Offshore Renewable Energy Conference, 2010.

[HOD 09] Hodgins N., Mcdonald A.S., SheK J.K.H., Keysan O., Mueller M.A., "Current and future developments of the C-GEN Lightweight Direct Drive Generator for Wave \& Tidal Energy", $8^{\text {th }}$ European Wave and Tidal Energy Conference, Uppsala, pp. 352-359, 2009.

[HOD 10] Hodgins N., Keysan O., Mcdonald A.S., Mueller M.A., "Linear generator for direct drive wave energy applications", ICEM 2010, 2010.

[KNA 00] Knapp W., Holmén E., Schilling R., "Considerations for water turbines to be used in wave energy converters", $4^{\text {th }}$ European Wave Energy Conference, Aalborg, 2000.

[KOF 06] Kofoed J., FrigaArd P., FriIs-Madsen E., Sorensen H., "Prototype testing of the wave energyconverter wave dragon", Renewable Energy, vol. 31, February 2006, pp. 181-189. 
[Lei 08] Leijon M., Bostrom C., Danielsson O., Gustafsson S., Haikonen K., Langhamer O., Strömstedt E., StÅlberg M., Sundberg J., Svensson O., Tyrberg S., WATERS R., "Wave Energy from the North Sea: experiences from the Lysekil research site", Surveys in Geophysics, vol. 29, pp. 221-240, October 2008.

[LEI 06] Leijon M., Danielsson O., Eriksson M., Thorburn K., Bernhoff H., Isberg J., Sundberg J., Ivanova I., Sjostedt E., Agren O., "An electrical approach to wave energy conversion”, Renewable Energy, vol. 31, pp. 1309-1319, July 2006.

[MAR 09] MARgheritini L., VicinanZa D., FrigaARd P., "SSG wave energy converter: Design, reliability and hydraulic performance of an innovative overtopping device", Renewable Energy, vol. 34, pp. 1371-1380, May 2009.

[MCD 08] MCDONALD A.S., Structural analysis of low speed, high torque electrical generators for direct drive renewable energy converters, $\mathrm{PhD}$ Thesis, University of Edinburgh, 2008.

[MCD 08] Mcdonald A.S., Hodgins N., Crozier R., Mueller M.A., "Integrated design of electrical generators for wave and tidal current energy converters", $2^{\text {nd }}$ International Conference on Ocean Energy, Brest, 2008, pp. 1-7.

[MIC 99] MicheL W. H., "Sea spectra revisited”, Marine Technology, vol. 36, no.4, pp. 211227, 1999.

[MUE 02] MuELLER M.A., "Electrical generators for direct drive wave energy converters", IEE Proceedings - Generation, Transmission and Distribution, vol. 149, p. 446, 2002.

[NeU 07] Neumann F., Brito-Melo A., Didier E., Sarmento A., "Pico OWC Recovery Project: recent activities and performance data", $7^{\text {th }}$ European Wave and Tidal Energy Conference, Porto, 2007.

[PEL] Pelamis Wave Power, http://www.pelamiswave.com/, April 2011.

[POL 00] POLINDER H., GARDNER F., VRIESEMA B., "Linear PM generator for wave energy conversion in the AWS", $8^{\text {th }}$ International Conference on Electrical Machines, Espoo, 2000 .

[POL 02] Polinder H., DAMEN M.E.C., GARDNER F., "Modelling and test results of the AWS linear PM generator system", $9^{\text {th }}$ International Conference on Electrical Machines, Bruges, 2002.

[POL 04] Polinder H., DAMEN M.E.C., GARDNER F., "Linear PM Generator System for wave energy conversion in the AWS", IEEE Trans. on Energy Conversion, vol. 19, pp. 583589, September 2004.

[POL 05] Polinder H., DAMEN M.E.C., GARDNer F., "Design, modelling and test results of the AWS PM linear generator", European Transactions on Electrical Power, vol. 15, pp. 245-256, May 2005.

[POL 07] Polinder H., DAmEN M.E.C., GARDNER F., "Linear Generator Systems for wave energy conversion", $7^{\text {th }}$ European Wave and Tidal Energy Conference, 2007. 
[PRE 04] Previsic M., Bedard R., Hagerman G., Siddiqui O., System level design. performance and costs, San Francisco California Energetech Offshore Wave Power Plant, 2004.

[RAM 99] Ramos C., Da Silva P.M., Carvalho A., "Current source inverter for a $400 \mathrm{~kW}$ ocean waves induction generator", European Conference on Power Electronics and Applications, vol. 855, 1999.

[RUE 07] RuELlan M., Méthodologie de dimensionnement d'un système de récupération de l'énergie des vagues, PhD Thesis, École Normale Supérieure de Cachan, 11 December 2007.

[SAL 74] SAlter S., "Wave power", Nature, vol. 249, p. 720-724, June 1974.

[SAL 89] SALTER S., "World progress in wave energy-1988", International Journal of Ambient Energy, vol. 10, p. 3-24, January 1989.

[SAU 09] SAULNIER J.B., Climatologie fine des systèmes de vagues pour l'étude des systèmes houlomoteurs, PhD Thesis, École Centrale de Nantes, 4 December 2009.

[THO04] ThORPE T., "Wave energy", Chapter 15 of Survey of Energy Resources, World Energy Council, p. 401-417, 2004.

[TIS 08] TisSANDier J., BABARIT A., ClÉMENT A.H., "Study of the smoothing effect on the power production in an array of SEAREV wave energy converters", $18^{\text {th }}$ International Offshore and Offshore and Polar Engineering Conference, International Society of Offshore and Polar Engineers, USA, 2008, pp. 1-7.

[Whi 07] Whittaker T., Collier D., Folley M., Osterried M., Henry A., Crowley M., "The development of Oyster a shallow water surging wave energy converter", $7^{\text {th }}$ European Wave and Tidal Energy Conference, Porto, 2007. 